ARTIGO

\title{
ATUAÇÃO DOS GOVERNOS DOS ESTADOS DE ALAGOAS E MARANHÃO NO FINANCIAMENTO DA EDUCAÇÃO INFANTIL
}

\author{
NICANOR M. LOPES ${ }^{1}$ \\ ORCID: https://orcid.org/0000-0002-0593-2873 \\ THERESA ADRIÃO ${ }^{2}$ \\ ORCID: https://orcid.org/0000-0003-1181-5873 \\ GABRIELA CRISTINA RAMOS ${ }^{3}$ \\ ORCID: https://orcid.org/0000-0002-4625-3228
}

\begin{abstract}
RESUMO: O texto analisa a atuação dos governos estaduais de Alagoas e Maranhão na destinação dos recursos em Manutenção e Desenvolvimento de Ensino (MDE) para o atendimento à educação infantil. Os estados foram selecionados tendo em vista o baixo PIB per capita, condição que exigiria maior participação dos governos estaduais em acordo com o regime de colaboração para a efetivação do atendimento educacional nesta etapa. O período (2005-2015) refere-se à primeira década da vigência da Lei de Responsabilidade Fiscal. Analisam-se dados primários disponíveis no SIOPE: receitas e despesas com educação infantil dos governos elencados e destinação dos recursos para o setor privado. Verificouse, assim, a pouca atuação dos governos estaduais na manutenção da educação infantil, sobrecarregando os orçamentos municipais e induzindo à privatização, evidenciada nos aumentos de gastos de MDE com setor privado e diminuição das matrículas públicas. A apreciação reforça a necessidade de mais estudos sobre gastos educacionais efetuados por municípios
\end{abstract}

Palavras-chave: Financiamento, Educação infantil, Privatização, Alagoas, Maranhão.

\section{ACTION BY THE GOVERNMENTS OF THE STATES OF ALAGOAS AND MARANHÃO IN THE FINANCING OF CHILD EDUCATION}

\begin{abstract}
The text analyzes Maranhão's and Alagoas' state governments actions regarding allocation of resources for "Maintenance and Development of Teaching" in order to assist early childhood education. The states were selected because of the low per capita GDP index, a condition that would require a greater participation of states governments in accordance with the "collaboration regime" (regime de colaboração) for the realization of educational supply at this stage. The period (2005-2015) refers to the first decade of the "Tax Liability Act" (Lei de Responsabilidade Fiscal). The current paper analyzes primary data available on SIOPE, namely: revenue and expenditure with early childhood

\footnotetext{
${ }^{1}$ Mestrando em Educação no Programa de Pós-Graduação da Universidade Estadual de Campinas (Unicamp). Campinas, SP, Brasil.<nicanormateuslopes@gmail.com>

2 Professora Colaboradora junto ao Programa de Pós-Graduação da Universidade Estadual de Campinas. Campinas, SP, Brasil. <theadriao@gmail.com>

${ }^{3}$ Graduada em Pedagogia pela Universidade Estadual de Campinas e professora da rede pública Municipal de Paulínia-SP. Campinas, SP, Brasil. >ramos.gabrielac@gmail.com > 
education for the listed governments as well as the transfer of resources to the private sector. It was possible to identify low levels of performance of state governments towards the maintenance of early childhood education, which overloads cities' budgets and inducts privatizations, as evidenced both by the increases in "Maintenance and Development of Teaching" spending with the private sector and by the decline in public enrollment. The study reinforces the need for further analysis on educational spending by cities.

Keywords: Funding, Early Childhood Education, Privatization, Alagoas, Maranhão.

\section{DESEMPEÑO DE LOS GOBIERNOS DE LOS ESTADOS DE ALAGOAS Y MARANHÁO EN LA FINANCIACIÓN DE LA EDUCACIÓN EN LA PRIMERA INFANCIA}

RESÚMEN: El texto analiza el desempeño de los gobiernos estatales de Alagoas y Maranhão en la asignación de recursos para el Mantenimiento y Desarrollo de la Enseñanza para la educación y cuidado en la primera infancia. Los Estados fueron seleccionados considerando el bajo PIB per cápita, una condición que requeriría una mayor participación de los gobiernos estatales de acuerdo al régimen de colaboración para la eficacia de la atención educativa en esta etapa. El período (2005-2015) se refiere a la primera década de vigencia de la Ley de Responsabilidad Fiscal. Se analizan los datos primarios disponibles en el SIOPE: ingresos y gastos en educación de la primera infancia de los gobiernos enumerados y asignación de recursos al sector privado. Por lo tanto, hubo poco desempeño de los gobiernos estatales en el mantenimiento de la educación en la primera infancia, sobrecargando los presupuestos municipales e induciendo la privatización, evidenciado en aumentos en el gasto con el sector privado y disminución de la matrícula pública. La evaluación refuerza la necesidad de seguir realizando estudios sobre el gasto educativo realizados por los municípios

Palabras clave: : Financiamiento, Educación en la Primera Infancia, Privatización, Alagoas, Maranhão. 


\title{
INTRODUÇÃO
}

No Brasil, a responsabilidade pela oferta da educação é dividida entre os entes federados (União, estados, DF e municípios). Prioritariamente, cabe aos municípios a oferta da Educação Infantil ( 0 a 6 anos $^{4}$ ) e Ensino Fundamental (6 a 14 anos), e aos estados a do Ensino Médio (15 a 17 anos). Teoricamente, o regime de colaboração, operacionalizado por meio da redistribuição de recursos entre os entes e pelo apoio técnico para a consecução de políticas educativas, viabilizaria a diminuição das desigualdades territoriais e favoreceria o oferecimento da educação básica de forma menos desigual no âmbito de cada estado. Entretanto, o uso intencional do advérbio se deve à divulgação de estudos de Oliveira (2010), Araújo (2014) e Castro (2011), que atestam a necessidade de reforma tributária redistributiva em termos territoriais e estratos sociais, como condição para o enfrentamento às desigualdades no financiamento da educação pública.

Tal desigualdade foi agravada pela transferência da responsabilidade da maior parte da oferta da educação básica aos municípios. Refletindo sobre esse processo, Cury afirmava que

\begin{abstract}
A rigor, as políticas de descentralização, sobretudo se acompanhadas do atual modo vigente do pacto federativo, significam um repasse de responsabilidade dos escalões nacionais para os subnacionais. Se estes últimos não forem capazes de sustentar suas responsabilidades, o risco é o de haver um deslocamento do público para o privado e aí reside o risco maior de uma competitividade e seletividade, de corte mercadológico, pouco natural aos fins da educação (Cury, 2002, p. 196).
\end{abstract}

Além disso, como identificado por Adrião, Borghi e Domiciano (2010), na maior parte das redes públicas cabe aos municípios cumprir o dever do Estado no atendimento às demandas educacionais, que compreende a oferta de creches, pré-escolas e, no mínimo, os cinco primeiros anos do ensino fundamental. Para as autoras,

\begin{abstract}
paralelamente à ampliação das responsabilidades educativas no âmbito municipal, assiste-se a uma alteração no papel dos governos estaduais e federal, na medida em que assumem a função de monitorar e ou avaliar o desempenho dos alunos das escolas públicas, subtraindo-se, na maioria dos casos, da necessária colaboração técnica e financeira que os governos locais necessitam. Mesmo com a ampliação de recursos federais decorrente do Fundo de Desenvolvimento e Manutenção da Educação Básica (Fundeb) ${ }^{5}$, a maior parte do atendimento à escolaridade básica está sob a responsabilidade municipal (ADRIÃO, BORGHI; DOMICIANO, 2010, p. 286).
\end{abstract}

Nesses termos, nas regiões mais pobres que concentram os municípios com menor capacidade e autonomia tributária, sem a efetiva participação dos demais entes federados são significativos os impactos negativos na amplitude do acesso e na qualidade do atendimento.

Segundo Araújo (2012), o regime de colaboração, conforme previsão constitucional, busca o

equilíbrio do desenvolvimento e do bem-estar em âmbito nacional, ou seja, o regime de colaboração para a educação só pode ser regulamentado por Lei complementar, o que requer aprovação no Congresso Nacional por quórum qualificado.[..]Ainda é preciso levar em conta que, estando os fundamentos da Constituição Federal de 1988 ancorados no federalismo cooperativo, a intenção é equilibrar os conflitos federativos e garantir a mesma qualidade de vida para todos os cidadãos, independentemente da região, estado e cidade onde habitam (ARAÚJO, 2012, p. 523, grifo nosso).

\footnotetext{
${ }^{4}$ De acordo decisão do Supremo Tribunal Federal de 2018, apenas as crianças com seis anos completos em 31 de março do ano da matrícula deverão ser matriculadas no Ensino Fundamental.

${ }^{5}$ O Fundo de Manutenção e Desenvolvimento da Educação Básica e de Valorização dos Profissionais da Educação - Fundeb foi instituído pela Emenda Constitucional no 53, de 19 de dezembro de 2006 e regulamentado pela Medida Provisória $\mathrm{n}^{\circ} 339$, de 28 de dezembro do mesmo ano, convertida na Lei $n^{\circ} 11.494$, de 20 de junho de 2007, e pelos Decretos $n^{\circ} 6.253$ e 6.278, de 13 e 29 de novembro de 2007, respectivamente (FNDE). Disponível em: <https://www.fnde.gov.br/index.php/financiamento/fundeb/sobre-o-plano-ou-programa/sobre-o-fundeb>. Acesso em: 10 de out. de 2019.
} 
A desigualdade no Brasil se expressa em diferenças gritantes, como a verificada em 2011 entre o PIB per capita do município mais rico (Presidente Kennedy - ES, com R \$ 21.632,72, posição mantida até 2017) e do mais pobre da federação (Porangatu - MG, com R \$146,26, substituído por Novo Triunfo - Bahia). Entretanto, de acordo com dados do IBGE, em 2015, dos dez municípios com menor PIB per capita, oito eram maranhenses. O mapa PIB dos Municípios: PIB per capita ${ }^{6}$ explicita a concentração dos municípios mais pobres na região Nordeste, seguido pelos municípios localizados na região da Floresta Amazônica. Essa desigualdade descomunal também reflete na área educacional, tanto que se estima a taxa de analfabetismo na região nordeste ser quase o dobro da média do país (ARAÚJO, 2016). Essa desigualdade descomunal também reflete na área educacional, tanto que se estima a taxa de analfabetismo na região nordeste ser quase o dobro da média do país (ARAÚJO, 2016). Nessas condições, apesar da Educação Infantil ser de responsabilidade prioritária dos municípios (Art. 211 da Constituição Federal), é evidente a necessidade de maior participação dos demais entes federados no financiamento e na oferta da educação para crianças de 0 a 6 anos, de modo a possibilitar a realização do direito a esta etapa educacional a todos que a solicitem.

Os índices apontam que a situação é ainda mais alarmante no atendimento às crianças de zero a 3 anos, conforme verificado nas informações sobre matrículas públicas presentes no gráfico 1, elaborado a partir do período relativo à primeira década de vigência integral da Lei de Responsabilidade Fiscal (Lei Complementar nº 101, de 4 de mai. 2000).

\section{Gráfico 1- Matrículas Públicas e Privadas Totais em Creches - Regiões Brasil (2005-2015)}

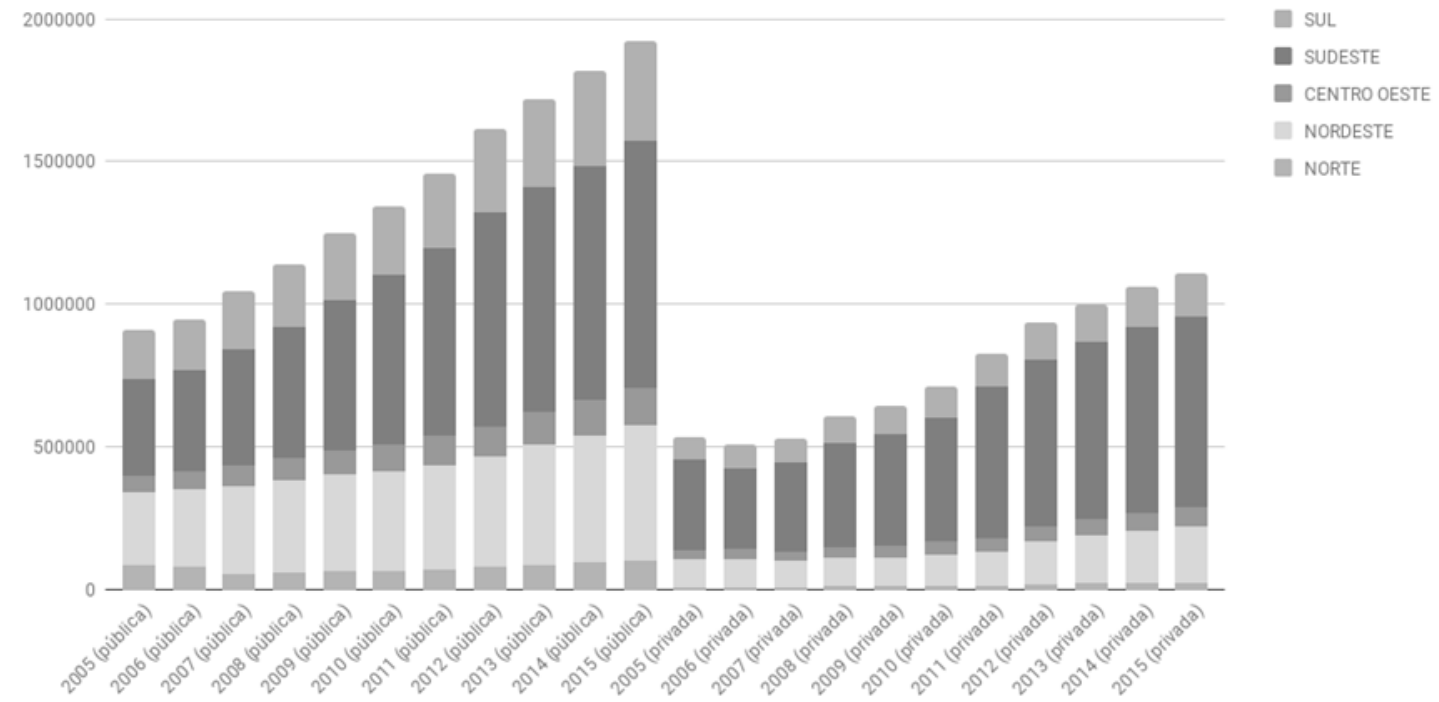

Fonte: ADRIÃO; GARCIA (Org.) 2018

Nota: considera-se matrículas públicas totais todas as matrículas urbanas e rurais em creches públicas somando redes municipais, estaduais e federal. E considera-se matrículas privadas totais a soma de todas as matrículas em creches privadas por região.

O gráfico1 indica, por região, a proporção de matrículas realizadas em creches públicas (soma das redes municipais, estaduais e federal) e privadas entre os anos de 2005-2015. De sua análise, e transformando os dados em número relativos, ou seja, em percentuais de atendimento por natureza das instituições educativas em cada região, depreende-se que, paralelamente à tendência de aumento do atendimento no período, há nas regiões mais pobres do país (Norte e Nordeste) um aumento nas matrículas das escolas privadas em relação as matrículas públicas. No Norte do país, as matrículas públicas cresceram $22,14 \%$, enquanto as privadas $133,9 \%$. Ainda segundo o gráfico 1, observa-se na região

${ }^{6}$ Disponível em: <https://www.ibge.gov.br/apps/pibmunic/>. Acesso em 9 de jun. de 2019.

Educação em Revista|Belo Horizonte |v.36|e231675|2020 
Nordeste do Brasil um aumento de 107,68\% nas matrículas privadas, enquanto as públicas cresceram $82,9 \%$.

Do ponto de vista jurídico e normativo, entre o final do século XX e o início do século XXI ampliou-se o direito à educação das crianças pequenas e o dever do Estado para com este direito. Citase a Constituição Federal de 1988 que garantiu o direito à educação das crianças de zero a seis anos; a Lei de Diretrizes e Bases da Educação Nacional, reconheceu a educação infantil como primeira etapa da Educação Básica (Lei 9394/96) e, posteriormente, a obrigatoriedade do ensino a partir dos 4 anos de idade (EC no 59/2009); o Plano Nacional de Educação, previu o atendimento de, no mínimo, metade das crianças com idade entre de 0 a 3 anos (Meta 1, LEI No 13.005/2014). Todas essas mudanças na legislação, incidiram diretamente na expansão da oferta na Educação Infantil. Entretanto, o gráfico 1 reafirma os estudos sobre o período analisado, segundo os quais, a expansão do atendimento a esta etapa da educação básica é ainda tímida diante da demanda potencial e das proposições presentes nos marcos legais em vigência (DIDONET, 2006; CÔRREA, 2011; PINTO, 2012; BARBOSA e ADRIÃO, 2016).

Ressalta-se que a efetivação das políticas e das estratégias governamentais que asseguraram a ampliação de direitos à Educação Infantil, limitou-se diante de um contexto de reforma da gestão pública brasileira (EC no 19/1998). Nela foi possível a regulamentação do uso de subsídios públicos para a oferta de serviços educacionais por instituições não governamentais, o modelo estruturante do atendimento em creches no Brasil (CAMPOS, 2006), e estímulo à transferência da oferta educativa para as organizações privadas, especialmente em decorrência da Lei de Responsabilidade Fiscal (Lei Complementar n. 101/2000), que resultou na fixação de um teto para gastos com despesa de pessoal (ADRIÃO, 2017; ADRIÃO e DOMICIANO, 2018). Em síntese, a configuração de um atendimento educacional para as crianças pequenas, historicamente assentado em convênios e contratos com organizações privadas, já havia se generalizado como estratégia dos prefeitos durante o FUNDEF (ARELARO, 2008), ampliada a partir do FUNDEB (PINTO, 2007) e estimulada pela LRF (ADRIÃO e DOMICIANO, 2018).

As desigualdades na distribuição dos tributos no território nacional e as especificidades da Educação Infantil, que apresenta um custo mais elevado quando comparado as demais etapas de escolaridade, são fatores que contribuem para uma maior precariedade no atendimento das crianças de zero a seis anos nas regiões mais pobres. Assim, com objetivo de colaborar para a compreensão dessa problemática, este estudo busca caracterizar a colaboração dos governos estaduais de Alagoas e Maranhão à oferta da educação infantil, a partir da análise dos volumes dos recursos vinculados destinados a este atendimento. Tal apreciação é complementada com dados relativos aos recursos destinados ao pagamento de atividades desenvolvidas pelo setor privado. Considerou-se, ainda, informações relativas às condições de funcionamento dos estabelecimentos educacional, desde a identificação de um conjunto mínimo de "condições de oferta" até a proporção de matrícula em função da população na faixa etária.

Apesar da educação infantil ser prioridade dos municípios, acredita-se que nos estados em que se concentram as cidades mais pobres do país, preservada a lógica do regime de colaboração, deveria ser mais efetivo o papel dos governos estaduais na garantia do direito a essa etapa de escolaridade. Esse foi o critério adotado para o estudo de Alagoas e Maranhão, selecionados tendo em vista que o PIB per capita de 2016, calculado pelo IBGE (Instituto Brasileiro de Geografia e Estatística) ${ }^{7}$, os colocavam nas últimas posições no ranking nacional. Destaca-se que não se trata de um trabalho comparativo com outros estados, ainda que se indique a necessidade de outras pesquisas para aferir um panorama nacional sobre a participação dos estados na Educação Infantil.

O período selecionado para a análise (2005 a 2015) corresponde à primeira década da vigência da Lei de Responsabilidade Fiscal (Lei Complementar no101, de 4 de maio 2000), a qual, dentre outras medidas, delimita os gastos do poder público com pessoal. Como a educação demanda gasto prioritariamente com contratações, ao fixar as despesas com pessoal em até $60 \%$ e sendo os municípios os entes federados com menor capacidade tributárias, a LRF induz à privatização desse atendimento por meio da ampliação de convênios ou contratos com organizações privadas (ADRIÃO e DOMICIANO,

\footnotetext{
${ }^{7}$ Disponível em: https://www1.folha.uol.com.br/mercado/2017/02/1861675-20-estados-tiveram-renda-per-capita-abaixoda-media-em-2016-diz-ibge.shtml. Acesso em: 20 de jun. 2018
} 
2018). Ainda na década selecionada, considera-se que a implantação do Fundo de Manutenção e Desenvolvimento da Educação Básica e de Valorização dos Profissionais da Educação (FUNDEB), por meio da Emenda Constitucional n ${ }^{\circ} .53$ de 19/12/2006 e regulamentado pela Lei no 11.494/2007, o qual incorporou as matrículas da educação infantil e do ensino médio, e suas modalidades na composição do fundo, política que impactou o atendimento na educação infantil, especialmente ampliando o atendimento privado com subsídio público a esta etapa educativa e a incidindo sobre a destinação de recursos de MDE. Entretanto, para efeito de analisarmos o recorte temporal e campo empírico adotados, ainda que considerem o FUNDEB, a análise prescinde da centralidade do Fundo ao entendimento do tema em questão: atuação dos governos estaduais para a efetivação do acesso à educação infantil.

No período, além do Fundeb, aprovou-se a Emenda Constitucional 59/2009 (BRASIL, 2009) que, dentre outras providências, alterou o Art. 208 da Constituição Federal incorporando à educação básica obrigatória o atendimento educacional a partir dos quatro anos de idade. Em síntese, tratou-se de um momento em que vigeram profundas alterações no desenho da oferta educacional e no papel reservado aos governos subnacionais brasileiros, alterações captadas pela série histórica.

Os procedimentos metodológicos envolveram pesquisa em fontes primárias nos Demonstrativos de Receitas e Despesas com Manutenção e Desenvolvimento do Ensino- MDE ${ }^{8}$ (somente em 2005); Relatório Resumido da Execução Orçamentária - RREO - Anexo X da Lei de Responsabilidade Fiscal (a partir de 2006); Demonstrativo na Função Educação; e Relatório de Dados Informados pelas Unidades da Federação: Despesas com Manutenção e Desenvolvimento do Ensino. Tais informações estão disponíveis no Sistema de Informações sobre Orçamentos Públicos em Educação (SIOPE), consultado entre fevereiro 2016 e julho de 2017. O SIOPE agrega informações oficiais "referentes aos orçamentos de educação da União, dos estados, do Distrito Federal e dos municípios" (FNDE, 2019) ${ }^{9}$

A partir das informações inventariadas, verificou-se o volume dos recursos de Manutenção e Desenvolvimento de Ensino direcionados ao setor privado por meio das aplicações registradas nas categorias econômicas: 3.33.90.39 - Outros Serviços de Terceiros - Pessoa Jurídica e 3.33.50.00 Transferências às Instituições Privadas Sem Fins Lucrativos. Analisou-se, também, o volume repassado para estas categorias econômicas em relação ao montante total do gasto com MDE na subfunção ${ }^{10}$ Educação Infantil, em cada um dos dois estados, Alagoas e Maranhão. A atualização dos valores derivou do uso de ferramenta disponível no site do easycalc (http://drcalc.net/), de acordo com Índice Nacional de Preços ao Consumidor (INPC) de julho de $2018^{11}$.

Para a caracterização da oferta da educação infantil em Alagoas e Maranhão, considerou-se a evolução do número de matrículas públicas (todas as dependências) e privadas em creche e pré-escola; o número de estabelecimentos educativos que ofertavam creche e pré-escola, bem como as informações disponíveis nos microdados do Censo Escolar sobre um conjunto de insumos considerados essenciais para realização do atendimento a crianças pequenas. Com o intuito de validação destas informações foram consultados dados do Censo Escolar/INEP, disponíveis nas Sinopses Estatísticas da Educação Básica $^{12}$ (2005-2015), enquanto os dados sobre insumos foram selecionados do conjunto de informações

\footnotetext{
${ }^{8}$ De acordo com o Art. 213 (CF/88): “Os recursos públicos serão destinados às escolas públicas, podendo ser dirigidos a escolas comunitárias, confessionais ou filantrópicas, definidas em lei, que: I - comprovem finalidade não lucrativa e apliquem seus excedentes financeiros em educação; II - assegurem a destinação de seu patrimônio a outra escola comunitária, filantrópica ou confessional, ou ao poder público, no caso de encerramento de suas atividades". http://inep.gov.br/web/guest/sinopses-estatisticas-da-educacao-basica.

${ }^{9}$ Disponível em: <http://www.fnde.gov.br/fnde_sistemas/siope>. Acesso em: 15 de setembro de 2019

10 Subfunção: divisão administrativa regulamentada pela portaria MPOG no 42, de 14 de abril de 1999, na qual considera a Educação como uma função administrativa e ensino fundamental, ensino médio, educação profissional, superior, infantil, EJA e especial como subfunções.

11 Considerou-se para efeito de cálculo de atualização monetária, o período de dezembro de cada ano analisado para "Mês/Ano início" até julho de 2018 para "Mês/Ano final", multiplicando os valores encontrados no SIOPE pelo fator de correção gerado na ferramenta.

${ }^{12}$ Disponível em: <http://inep.gov.br/web/guest/sinopses-estatisticas-da-educacao-basica>. Acesso em: 08 de ago. 2019 Educação em Revista|Belo Horizonte|v.36|e231675|2020
} 
que integram o Censo Escolar/INEP, disponíveis para consulta nos microdados ${ }^{13}$ (2005-2015). Destacase, ainda, consulta junto ao portal Laboratório de Dados Educacionais ${ }^{14}$

Por fim, com o objetivo de compor o contexto no qual a atuação dos governos estaduais para a realização do direito à educação infantil foi percebida, o artigo considera os valores do Produto Interno Bruto relacionando com os partidos de filiação dos governadores dos respectivos estados no período analisado.

O texto organiza-se em três partes com objetivos específicos, além da introdução e considerações finais. Na primeira, apresenta informações sobre o atendimento à educação infantil (creche e pré-escola) nos estados de Maranhão e Alagoas, com vistas a explicitar a atuação das diferentes esferas administrativas na série histórica. No segundo item, indica a proporção com que os insumos considerados mínimos à oferta adequada da educação infantil pública são identificados nos estabelecimentos públicos que oferecem a creche e pré-escola. Tais insumos foram selecionados com base nas pesquisas de Carreira e Pinto (2007) que formularam o mecanismo do Custo Aluno Qualidade Inicial (CAQi), de Passador e Alves (2011) que geraram um Índice de Condições de Oferta (Icoe), e de Sampaio e Oliveira (2015) um estudo relativo à desigualdade educacional, visando apresentar a necessidade de maior interferência dos governos dos estados selecionados nas escolas de educação infantil. Já na terceira parte, discute os gastos desses governos na subfunção educação infantil, registrados nos relatórios disponíveis no SIOPE entre os anos de 2005 a 2015. Visando, assim, apresentar os valores repassados para educação infantil e relacioná-los aos volumes destinados ao setor privado via despesas realizadas nas categorias econômicas: Outros Serviços de Terceiros - Pessoa Jurídica e Transferências às Instituições Privadas Sem Fins Lucrativos. Destaca-se que, no caso de Alagoas, os dados relativos a 2014 e 2015 não foram disponibilizados para consulta durante o período de coleta, razão pela qual, nesse estado, as despesas e receitas consideradas correspondem ao período de 2005 a 2013.

O estudo desenvolveu-se no âmbito do grupo de Estudos e Pesquisas em Política Educacional - GREPPE e vincula-se ao projeto Gastos estaduais de MDE realizados com o setor privado $(2005-2015)^{15}$. Trata-se, em síntese, de uma contribuição ao debate sobre a divisão de responsabilidades entre os entes federados subnacionais à garantia do direito à educação de crianças pequenas.

\section{MATRÍCULAS NA EDUCAÇÃO INFANTIL NOS ESTADOS DE ALAGOAS E MARANHÃO (2005-2015)}

\section{Alagoas:}

O estado de Alagoas possui 102 municípios e, em 2015, sua população residente era de 3.344.961 pessoas (IBGE/PNAD, 2015) ${ }^{16}$. Nesse mesmo ano, o estado apresentava uma população de 328.887 de crianças de 0 a 5 anos (sendo 215.628 de 0 a 3 anos e 113.259 de 4 e 5 anos), o que corresponde cerca de $10 \%$ da população total. De acordo com Plano Estadual de Alagoas (2015), o estado atendia apenas $20,7 \%$ da demanda por educação de crianças de 0 a 3 anos e 75,6\% da pré-escola (ALAGOAS, 2015):

Entre 2000 e 2010, observa-se um decréscimo populacional dessa faixa etária, causado provavelmente, pela alta taxa de mortalidade infantil, pelo êxodo rural e pela implantação de políticas de controle de natalidade e de garantia do acesso a escolarização, tanto na área rural quanto na urbana, sendo a área rural a mais afetada (ALAGOAS, 2015, p. 17).

Os gráficos 1 e 2 mostram que, em todo o período, houve predomínio de matrículas da educação infantil (creche e pré-escola) nas redes públicas, com explicito predomínio das matrículas municipais. No caso do atendimento de crianças de 0 a 3 anos (gráfico 1), nesse período, as matrículas

\footnotetext{
${ }_{13}$ Disponível em: <http://inep.gov.br/microdados>. Acesso em: 10 de ago. 2019

${ }^{14}$ Disponível em: <https://dadoseducacionais.c3sl.ufpr.br/\#/>. Acesso em: 20 de ago. 2019

15 Coordenada por ADRIÃO e DOMICIANO; 2016.

${ }^{16}$ Disponível em: <https://sidra.ibge.gov.br/tabela/261\#resultado>. Acesso em: 15 de ago. 2019 
aumentaram na rede pública e privada concomitantemente e de maneira significativa, sendo a taxa de crescimento de $245,23 \%$ na rede pública e $191,40 \%$ na privada.

Gráfico 1: Matrícula públicas, municipais e privadas- CRECHE / Alagoas (2005-2015)

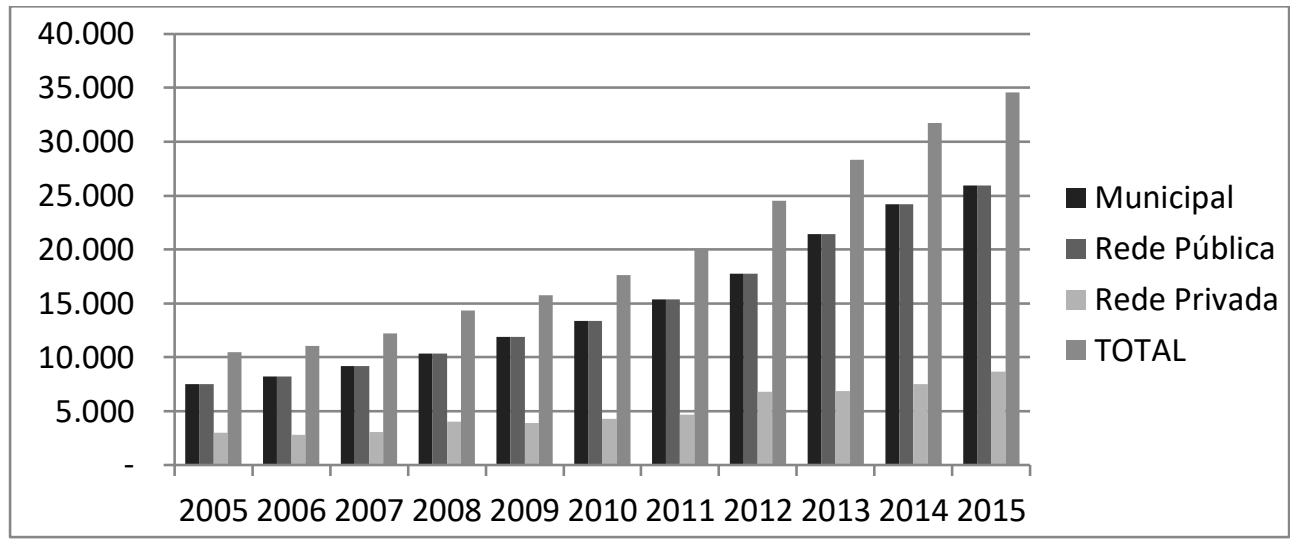

Fonte: pesquisa ADRIÃO (coord.); DOMICIANO; 2016.

Já na pré-escola (gráfico 2), a matrícula total oscilou pouco, mas indicou uma diminuição de 6,23\% da oferta pública entre 2005 e 2015, ainda que tenha sido ampliada no ano de 2006. Paralelamente, a partir de 2010, observa-se um aumento significativo na oferta privada da pré-escola gerando um aumento de $27,11 \%$ nas matrículas privadas.

\section{Gráfico 2: Matrícula públicas/municipais e privadas. PRE- ESCOLA- Alagoas (2005-2015)}

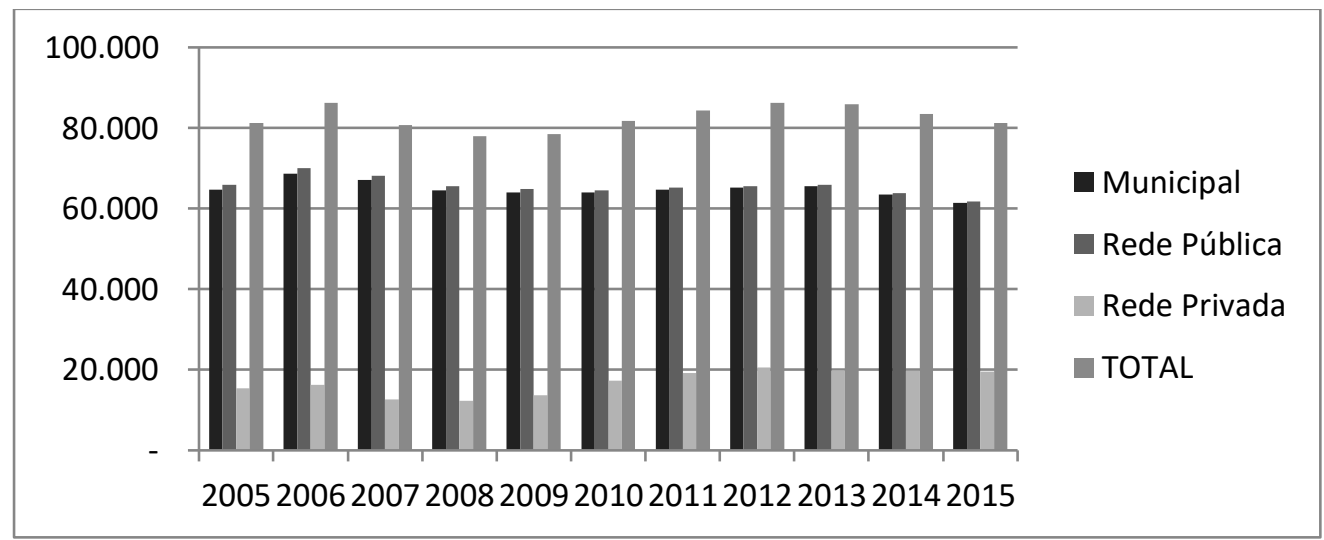

Fonte: pesquisa ADRIÃO (coord.); DOMICIANO; 2016.

A tabela 1 permite identificar a intensidade com que as diferentes esferas administrativas se fizeram presentes no atendimento à creche. Nota-se que houve um crescimento do atendimento nessa etapa em Alagoas e isto não decorreu da atuação direta do governo estadual. No caso da pré-escola, a participação do governo do estado na oferta direta é pequena $(1,42 \%)$ em 2005 , diminuiu um pouco mais de $72 \%$ ao longo da década, representando $0,39 \%$ de matrículas estaduais na pré-escola em relação ao total de matrículas na mesma etapa no ano de 2015. Ainda no que concerne ao atendimento na préescola, observou-se a diminuição da oferta na rede pública e o aumento na rede privada. Mesmo não sendo possível estabelecer uma correlação direta, identifica-se que a queda das matrículas na pré-escola, a partir de 2006, coincide com a Lei 11.274/2006 que regulamenta o ensino fundamental de 9 anos. 
Tabela 1: Número de Matrículas Creche e Pré-escola por dependência administrativa- Alagoas (2005-2015)

\begin{tabular}{|c|c|c|c|c|c|c|c|c|c|c|c|c|}
\hline ETAPA & DEPENDÊNCIA & 2005 & 2006 & 2007 & 2008 & 2009 & 2010 & 2011 & 2012 & 2013 & 2014 & 2015 \\
\hline \multirow{6}{*}{ Creche } & Municipal & 7.508 & 8.217 & 9.202 & 10.315 & 11.884 & 13.341 & 15.391 & 17.731 & 21.461 & 24.204 & 25.917 \\
\hline & Estadual & - & - & - & - & - & - & - & - & - & - & 3 \\
\hline & Federal & - & - & - & - & - & - & - & - & - & - & - \\
\hline & Rede Pública & 7.508 & 8.217 & 9.202 & 10.315 & 11.884 & 13.341 & 15.391 & 17.731 & 21.461 & 24.204 & 25.920 \\
\hline & Rede Privada & 2.976 & 2.804 & 3.030 & 4.013 & 3.894 & 4.291 & 4.683 & 6.808 & 6.841 & 7.527 & 8.672 \\
\hline & TOTAL & 10.484 & 11.021 & 12.232 & 14.328 & 15.778 & 17.632 & 20.074 & 24.539 & 28.302 & 31.731 & 34.592 \\
\hline \multirow{6}{*}{ Pré-escola } & Municipal & 64.717 & 68.657 & 67.025 & 64.593 & 64.079 & 63.965 & 64.698 & 65.249 & 65.597 & 63.494 & 61.443 \\
\hline & Estadual & 1.150 & 1.301 & 1.051 & 946 & 812 & 555 & 494 & 323 & 297 & 322 & 320 \\
\hline & Federal & - & - & - & - & - & - & - & - & - & - & - \\
\hline & Rede Pública & 65.867 & 69.958 & 68.076 & 65.539 & 64.891 & 64.520 & 65.192 & 65.572 & 65.894 & 63.816 & 61.763 \\
\hline & Rede Privada & 15.358 & 16.333 & 12.592 & 12.341 & 13.669 & 17.220 & 19.110 & 20.594 & 19.961 & 19.717 & 19.522 \\
\hline & TOTAL & 81.225 & 86.291 & 80.668 & 77.880 & 78.560 & 81.740 & 84.302 & 86.166 & 85.855 & 83.533 & 81.285 \\
\hline
\end{tabular}

Fonte: pesquisa ADRIÃO (coord.); DOMICIANO; 2016. com base em dados do censo escolar disponíveis em INSTITUTO NACIONAL DE ESTUDOS E PESQUISAS EDUCACIONAIS ANÍSIO TEIXEIRA. Sinopse Estatística da Educação Básica 2005-2015 Brasília. Inep, 2005, 2006, 2007, 2008, 2009, 2010, 2011, 2012, 2013, 2014, 2015. Disponível em http://portal.inep.gov.br/sinopses-estatisticas-daeducacao-basica>. Acesso em out/nov de 2018.

\section{Maranhão:}

O estado do Maranhão possui 217 municípios e, em 2015, sua população era de 6.910.367 pessoas (IBGE/PNAD, 2015); a população residente de 0 a 4 anos representava $8,5 \%$ da população total. De acordo com Plano Estadual do Maranhão (2015), no ano de 2010, o estado atendia apenas 20,2\% da demanda na educação de crianças de 0 a 3 anos e $88,2 \%$ da pré-escola.

$\mathrm{Na}$ análise dos dados da oferta da educação infantil no estado do Maranhão, demonstrados na tabela 1 , há o predomínio de matrículas na rede pública, com número significativo em dependências municipais.

O gráfico 3 ilustra o aumento expressivo no total de matrículas em creches entre os anos de 2005 e 2015.

\section{Gráfico 3: Tendências das matrículas públicas/ municipais e privadas em creches no estado do Maranhão (2005-2015)}

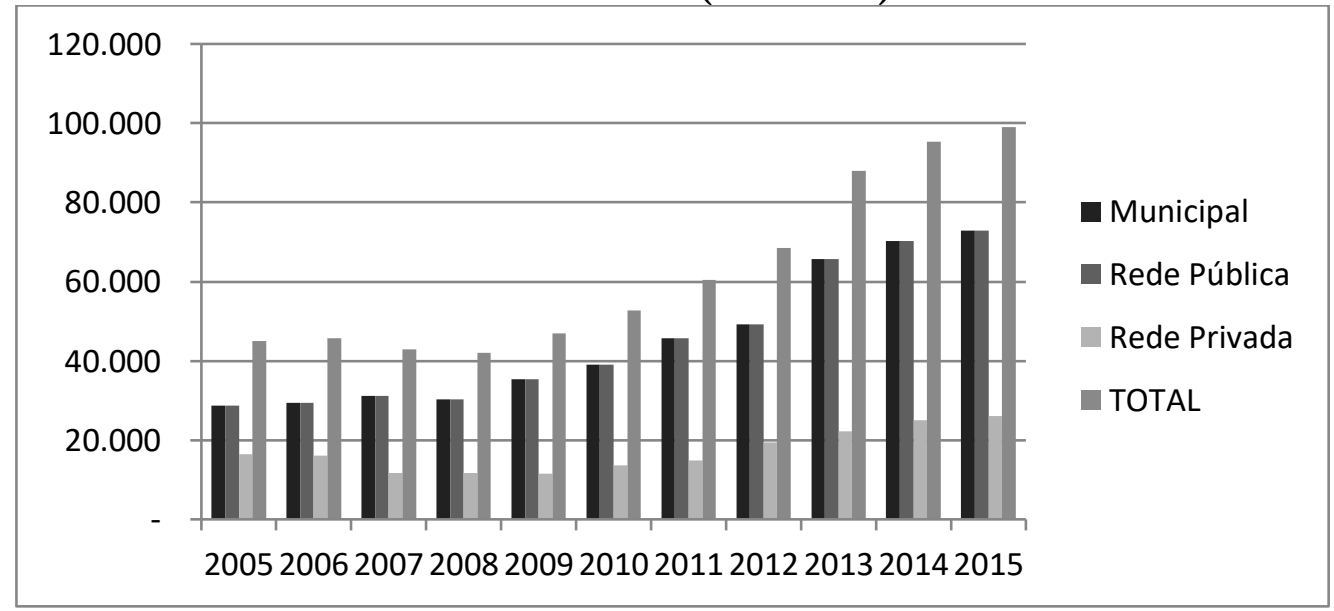

Fonte: pesquisa ADRIÃO (coord.); DOMICIANO; 2016

Nota: As poucas matrículas estaduais no período são encontradas apenas em 2008 e 2010 . Cf. tabela 2.

Considerando-se as matrículas em 2005 e 2015, nota-se um aumento de 154,76\% na oferta municipal e de $58,44 \%$ nas matrículas em instituições privadas.

Já em relação à Pré-escola, o gráfico 4 mostra o decréscimo de 21,4\% no atendimento pelas redes públicas e de 38,26\% na rede privada para alunos de 4 a 6 anos. 
Gráfico 4: Tendências das Matrículas públicas/municipais e privadas em pré-escola no estado do Maranhão (2005-2015)

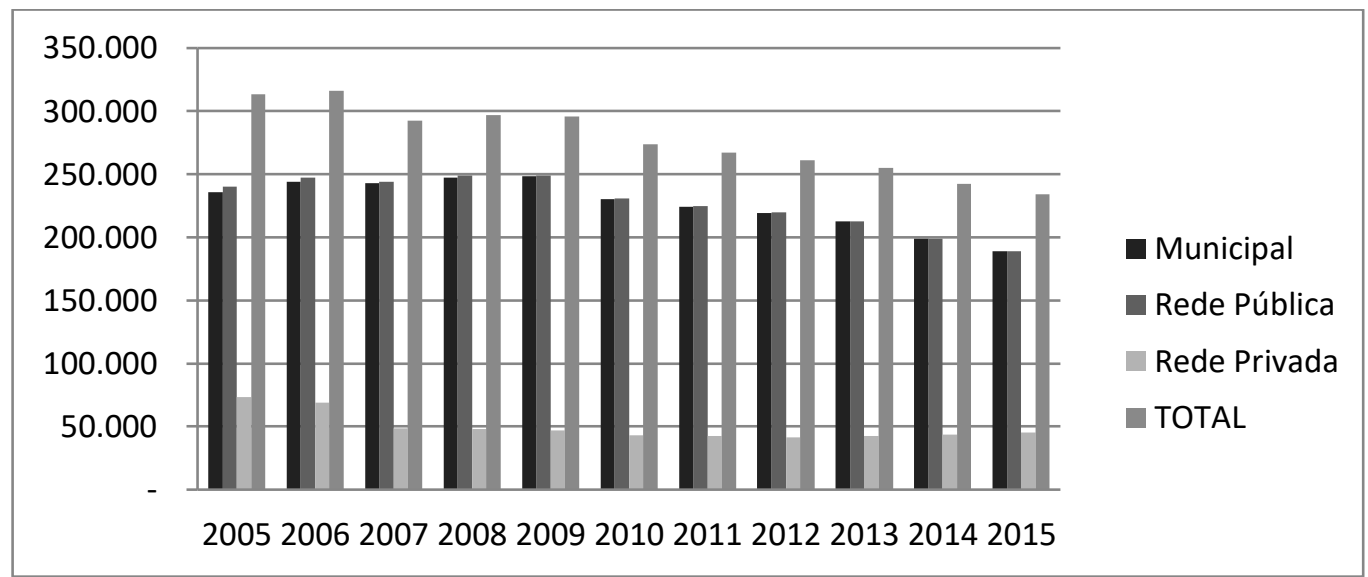

Fonte: pesquisa ADRIÃO (coord.); DOMICIANO; 2016.

Destaque para o ano de 2010 que registrou quedas de 7,87\% de matrículas na rede pública e de $8,83 \%$ na rede privada em relação a 2009 .

A tabela 2 demonstra, em números, a ausência de participação do governo estadual maranhense na oferta direta de creches e a diminuição de sua atuação nas matrículas diretas na pré-escola. Mesmo correspondendo a $1,33 \%$ do atendimento total no início da série, houve uma diminuição de $0,06 \%$ no ano de 2015 .

Tabela 2: Número de Matrículas na Educação Infantil no estado do Maranhão (2005-2015)

\begin{tabular}{|c|c|c|c|c|c|c|c|c|c|c|c|c|}
\hline ETAPA & DEPENDÊNCIA & 2005 & 2006 & 2007 & 2008 & 2009 & 2010 & 2011 & 2012 & 2013 & 2014 & 2015 \\
\hline \multirow{6}{*}{ Creche } & Municipal & 28.625 & 29.473 & 31.112 & 30.340 & 35.425 & 39.054 & 45.695 & 49.181 & 65.744 & 70.277 & 72.926 \\
\hline & Estadual & - & - & - & 14 & - & 57 & - & - & - & - & 7 \\
\hline & Federal & - & - & - & - & - & - & - & - & 66 & - & - \\
\hline & Rede Pública & 28.625 & 29.473 & 31.112 & 30.354 & 35.425 & 39.111 & 45.695 & 49.181 & 65.744 & 70.277 & 72.933 \\
\hline & Rede Privada & 16.405 & 16.153 & 11.745 & 11.744 & 11.487 & 13.563 & 14.814 & 19.343 & 22.153 & 24.985 & 25.992 \\
\hline & Total & 45.030 & 45.626 & 42.857 & 42.098 & 46.912 & 52.674 & 60.509 & 68.524 & 87.897 & 95.262 & 98.925 \\
\hline \multirow{6}{*}{ Pré-escola } & Municipal & 235.755 & 244.089 & 242.861 & 247.556 & 248.664 & 230.487 & 224.292 & 219.518 & 212.681 & 198.860 & 188.830 \\
\hline & Estadual & 4.172 & 3.313 & 920 & 1.418 & 368 & 367 & 206 & 150 & 75 & 104 & 144 \\
\hline & Federal & - & - & - & - & - & - & - & - & - & - & - \\
\hline & Rede Pública & 239.927 & 247.402 & 243.781 & 248.974 & 249.032 & 230.854 & 224.498 & 219.668 & 212.756 & 198.964 & 188.974 \\
\hline & Rede Privada & 73.339 & 68.945 & 48.543 & 47.906 & 46.710 & 42.920 & 42.567 & 41.242 & 42.465 & 43.621 & 45.278 \\
\hline & Total & 313.266 & 316.347 & 292.324 & 296.880 & 295.742 & 273.774 & 267.065 & 260.910 & 255.221 & 242.585 & 234.252 \\
\hline
\end{tabular}

Fonte: pesquisa ADRIÂO (coord.); DOMICIANO; 2016. Com base em dados do censo escolar disponíveis em INSTITUTO NACIONAL DE ESTUDOS E PESQUISAS EDUCACIONAIS ANÍSIO TEIXEIRA. Sinopse Estatística da Educação Básica 2005-2015 Brasília. Inep, 2005, 2006, 2007, 2008, 2009, 2010, 2011, 2012, 2013, 2014, 2015. Disponível em: <http://portal.inep.gov.br/sinopses-estatisticas-daeducacao-basica>. Acesso em: out/nov de 2018.

\section{Alagoas e Maranhão- Diálogos sobre a oferta:}

Nesses estados houve, no período pesquisado, um aumento do atendimento de crianças de 0 a 3 anos pelas redes municipais e por escolas privadas. Já para o acesso à pré-escola, o Maranhão apresentou redução em todas as esferas administrativas públicas, enquanto as matrículas em escolas privadas aumentaram a partir de 2013, depois de consecutivas quedas entre 2005 e 2012. Ou seja, ainda que o predomínio das matrículas de pré-escola no estado do Maranhão seja na esfera municipal, observou-se um aumento da oferta privada concomitantemente à diminuição da pública.

A tabela 3 ilustra a taxa de variação média nas matrículas em creches e pré-escolas públicas e privadas em Alagoas e Maranhão. 
Tabela 3: Variação média de matrículas em creche e pré-escola entre 2005 e 2015 (\%) - Alagoas (AL) e Maranhão (MA)

\begin{tabular}{c|cc|cc}
\multicolumn{2}{c}{ DEPENDÊNCIA } & \multicolumn{2}{c}{ AL } \\
\hline \multirow{2}{*}{ Rede Pública } & Creche & 12,52 & Creche & $\mathbf{7 , 2 6}$ \\
& Pré-escola & $-0,78$ & Pré-escola & $\mathbf{- 2 , 4 5}$ \\
\hline \multirow{2}{*}{ Rede Privada } & Creche & 10,03 & Creche & $\mathbf{9 , 2 2}$ \\
& Pré-escola & 0,06 & Pré-escola & $\mathbf{- 2 , 5 0}$ \\
\hline
\end{tabular}

Fonte: pesquisa ADRIÃO (coord.); DOMICIANO; 2016.

Nota: Variação média é a média aritmética da variação anual na série histórica (2005-2015) para cada etapa da educação infantil.

Observa-se, nesses estados, uma variação positiva das matrículas em creche $12,52 \%$ na oferta pública e 10\% na privada em Alagoas, enquanto no Maranhão o aumento no atendimento contou com maior participação da oferta privada, $9,22 \%$ contra 7,26\% na oferta pública.

Em ambos, conforme explicitado na tabela 4, os governos estaduais são omissos na oferta direta de creches para seus cidadãos. Em relação à pré-escola, observa-se queda nas matrículas públicas em Alagoas e em ambas as esferas (pública e privada) no Maranhão. Nessa tabela, buscou-se relacionar a oferta direta de vagas para a educação infantil por parte dos governos estaduais pesquisados com os partidos aos quais se filiavam os governadores em exercício durante o período, juntamente com a variação do PIB. Em Alagoas, entre 2007 e 2014, maior parte do período, o estado foi administrado pelo governador Teotônio Vilela Filho, vinculado ao Partido da Social Democracia Brasileira (PSDB). Observa-se que mesmo diante do aumento constante do PIB de 43,77\% no primeiro período (20052008), 55,65\% no segundo (2008-2012) e 33,81\% no terceiro (2012-2015), houve diminuição da oferta de vaga direta na pré-escola. No maior período de crescimento do PIB, 2008 a 2012, o governo alagoano registrou queda de $65,95 \%$ de matrículas de pré-escola.

Tabela 4: Anos selecionados com Matrículas estaduais em creche e pré-escola, PIB e partidos políticos do Governador/a de Alagoas e Maranhão.

$\begin{array}{cccccc} & & \mathbf{2 0 0 5} & \mathbf{2 0 0 8} & \mathbf{2 0 1 2} & \mathbf{2 0 1 5} \\ \text { Partidos } & \text { Alagoas } & \text { PSB } & \text { PSDB } & \text { PSDB } & \text { MDB } \\ & \text { Maranhão } & \text { PFL } & \text { PDT } & \text { PMDB } & \text { PCdoB } \\ \text { PIB a Preços Correntes } & \text { Alagoas } & 15484521,00 & 22262295,00 & 34650397,00 & 46367211,00 \\ \text { (Mil Reais) } & \text { Maranhão } & 25104209,00 & 37932402,00 & 60490109,00 & 78475994,00 \\ & \text { Alagoas } & 0 & 0 & 0 & 3 \\ \text { Matrícula Creche Estadual } & \text { Maranhão } & 0 & 0 & 0 & 7 \\ \text { Matrícula Pré-Escola } & \text { Alagoas } & 1150 & 946 & 322 & 320 \\ \text { Estadual } & \text { Maranhão } & 4172 & 731 & 183 & 144\end{array}$

Fonte: autores com base em Barbosa e Adrião, 2016 (p. 186) e IBGE, em parceria com os Órgãos Estaduais de Estatística, Secretarias Estaduais de Governo e Superintendência da Zona Franca de Manaus - SUFRAMA. Disponível em: < https://www.ibge.gov.br/estatisticas/economicas/contas-nacionais/9088-produto-interno-bruto-dosmunicipios.html? $=\& \mathrm{t}=$ series-historicas\&utm_source=landing\&utm_medium=explica\&utm_campaign=pib $>$. Acesso em: out. de 2019. Nota: No estado do Maranhão em abril de 2009 o mantado do PDT é cassado assumindo a chapa do PMDB, segunda colocada nas eleições de 2006.

No Maranhão, o período estudado começa com a gestão de José Reinaldo Tavares do Partido Socialista Brasileiro (PSB), responsável pela diminuição abrupta das vagas estaduais para a pré-escola, da 
ordem de 82\%. Na sequência, com a cassação do governador do PDT em 2009, Roseana Sarney (PMDB) assumiu o governo do estado entre 2009 a 2014, e manteve a tendência de diminuição da oferta direta de vagas na pré-escola pelo governo. Em 2015, Flávio Dino, do Partido Comunista do Brasil (PCdoB), assume o governo do estado e a tendência de queda se mantem. Verifica-se, como em Alagoas, aumento no PIB, cerca de 51,10\% no primeiro período (2005-2008), 59,47\% no segundo (2008-2012) e 33,81\%, no último (2012-2015), condição que não representou o aumento da presença do governo estadual na garantia de vagas em pré-escolares.

Em síntese, em ambos e independentemente do partido que capitaneia o executivo, a presença do governo estadual na oferta de vagas para a educação infantil é inicialmente marginal e tende a ser nula. Essa ausência é agravada quando se observa o percentual da população na faixa etária correspondente, a quem não estava assegurado o acesso ao atendimento educacional, como indicado no gráfico 5. Observa-se a Taxa de Matrícula Líquida ${ }^{17}$ para os últimos três anos da série histórica, expressando o "percentual de pessoas matriculadas em determinada etapa da educação básica na faixa etária, teoricamente adequada a mesma etapa de ensino" (ALVES et al., 2019).

\section{Gráfico 5: Taxa de matrícula líquida nos estados do Maranhão e Alagoas - anos selecionados}

disponíveis

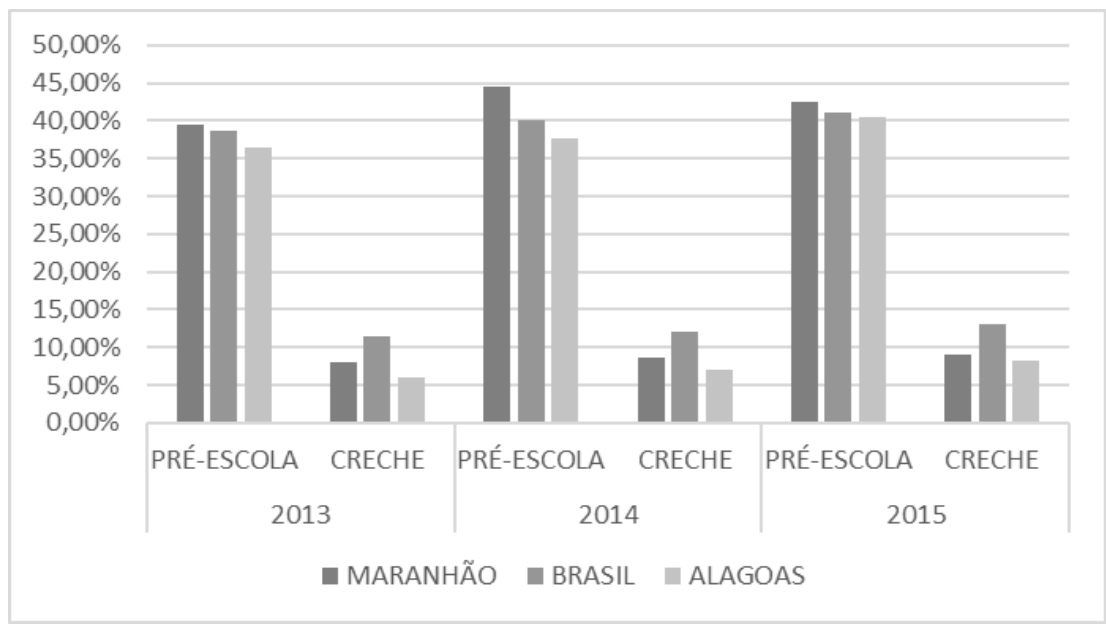

Fonte: os autores com base em Laboratório de Dados Educacionais a partir dos Censo Escolar/INEP (arquivo matrícula) e Pnad/IBGE (arquivo Pessoas) 2013 - 2015. Acesso em: jun. de 2019.

\section{CONDIÇÕES DE OFERTA DA EDUCAÇÃO INFANTIL NOS ESTADOS DO MARANHÃO E ALAGOAS}

O direito à educação, para além do acesso à educação infantil, por meio da disponibilidade de vagas a todas as crianças de 4 a 6 anos e a todas que demandarem dos 0 a 3 anos, viabiliza-se quando o atendimento ocorre em condições adequadas. A garantia de tais condições remonta à Anísio Teixeira (1968), quando este propôs o custo-padrão da educação, apresentando-se, ainda hoje, como importante componente para o enfretamento da desigualdade educacional.

Atualizando esta problemática, Carreira e Pinto (2007) sistematizam o mecanismo do Custo Aluno Qualidade Inicial (CAQi), incorporado ao texto do Plano Nacional de Educacional, segundo o

\footnotetext{
${ }^{17}$ Obtida pela fórmula matemática TML $=\left(\mathbf{M}_{\mathbf{k i}} / \mathbf{P}_{\mathbf{k i}}\right) \mathbf{x} 100$ onde: $\mathbf{M}_{\mathbf{k i}}=$ matrícula na etapa de ensino $\mathrm{k}$ pertencente à faixa etária i teoricamente adequada a esse nível; Pki= população na faixa etária i teoricamente adequada ao nível de ensino k. Onde: $\mathrm{i}$ = faixa etária teoricamente adequada ao nível $\mathbf{k} . \mathbf{k}=$ creche, pré-escola, ensino fundamental anos iniciais, ensino fundamental anos finais e ensino médio. A faixa etária foi calculada com base na idade da pessoa em 31/03 do ano da coleta de dados. Como idade teoricamente adequada para cada etapa da educação básica, considera-se: Creche - 0 a 3; Pré-Escola - 4 a 5; Anos iniciais do EF - 6 a 10; Anos Finais do EF - 11 a 14; Ensino Médio - 15 a 17 (ALVES, et al., 2019).

Educação em Revista|Belo Horizonte|v.36|e231675|2020
} 
qual alguns insumos são considerados essenciais para que a educação oferecida ocorra de acordo com os padrões mínimos de qualidade previstos no art. 212 de nossa Constituição. Tais condições, segundo os autores, envolvem aspectos como infraestrutura escolar, existência de equipamentos materiais pedagógicos adequados, formação e salário docente, etc. e devem constituir a base de cálculo para o financiamento da educação básica.

Outros estudos como os de Passador e Alves (2011) também se debruçaram sobre o tema e neste caso geraram um Índice de Condições de Oferta (Icoe), constituído por elementos análogos ao previsto para composição do CAQi.

Por fim, Sampaio e Oliveira (2015), em estudo relativo à desigualdade educacional adotam a formulação de desigualdade de tratamento para se referirem aos desiguais acessos aos insumos essenciais (quadro 1) a que estão submetidos grande parte da população mais pobre do Brasil. Para esses autores, a desigualdade de tratamento constitui-se em outra forma de negação de direito à educação, posto que este não se efetiva apenas com o acesso à escola. No caso brasileiro, essa desigualdade de tratamento é maior para as crianças de zero a três anos e jovens de 18 a 24 anos.

Em diálogo com essa literatura, especialmente com o mecanismo do CAQi, selecionamos um conjunto de insumos educacionais e condições de infraestrutura considerados básicos para o funcionamento minimamente adequado de equipamentos de educação infantil, apresentados como condições de oferta.

Para analisar tais condições (estabelecimentos municipais e estaduais) nos estados de Alagoas e Maranhão, desenvolveu-se uma abordagem quantitativa que utiliza como fontes os microdados do censo escolar referentes aos anos de 2005, 2010 e $2015^{18}$, disponibilizados pelo Instituto Nacional de Estudos e Pesquisas Educacionais Anísio Teixeira (INEP). Para leitura, organização e síntese dos microdados utilizou-se o programa IBM SPSS Statistics, selecionando as informações apresentadas no quadro 1.

\section{Quadro 1: Conjunto selecionado de insumos e infraestrutura considerados essenciais para o funcionamento minimamente adequado de creches e pré-escolas}

\begin{tabular}{llll}
\hline \multicolumn{1}{c}{ Serviços básicos } & Infraestrutura geral & $\begin{array}{l}\text { Infraestrutura } \\
\text { pedagógica }\end{array}$ & $\begin{array}{l}\text { Recursos pedagógicos e } \\
\text { assistenciais }\end{array}$ \\
\hline Acesso a água potável & Cozinha & Sala de Leitura & Acesso à internet \\
\hline Acesso à rede de água & Sanitário adequado & Biblioteca & Alimentação Escolar \\
\hline Energia elétrica & Berçário/fraldário & Parque Infantil & \\
\hline & Pátio coberto & Sala de TV & \\
\hline & Dormitório & Brinquedoteca & \\
\hline
\end{tabular}

Fonte: Autores em diálogo com Sampaio e Oliveira (2015), Passador e Alves (2011) e Carreira e Pinto (2007).

$\mathrm{Na}$ tabela 5 há informações sobre o total de estabelecimentos que ofertavam vagas em creches e pré-escolas nos estados de Alagoas e Maranhão, nos anos de 2005, 2010 e 2015. Destaca-se o aumento no número de equipamentos educativos oferecidos nas creches, tanto em Alagoas (250\% a mais em dez anos) quanto no Maranhão (873\% a mais em 10 anos). Ao passo que o número de estabelecimentos que ofertavam a pré-escola foi menor, mesmo com a previsão da obrigatoriedade a partir de 2017; com aumento de 9,87\% em Alagoas e 17,5\% no Maranhão, entre os anos de 2005 e 2015. No Brasil, a responsabilidade pela oferta da educação é dividida entre os entes federados (União, estados, DF e municípios). Prioritariamente, cabe aos municípios a oferta da Educação Infantil (0 a 6 anos ${ }^{19}$ e Ensino Fundamental (6 a 14 anos), e aos estados a do Ensino Médio (15 a 17 anos). Teoricamente, o regime de colaboração, operacionalizado por meio da redistribuição de recursos entre os entes e pelo

\footnotetext{
18 Agradecemos a colaboração da pesquisadora Nadia Drabach.

${ }^{19}$ De acordo decisão do Supremo Tribunal Federal de 2018, apenas as crianças com seis anos completos em 31 de março do ano da matrícula deverão ser matriculadas no Ensino Fundamental. 
apoio técnico para a consecução de políticas educativas, viabilizaria a diminuição das desigualdades territoriais e favoreceria o oferecimento da educação básica de forma menos desigual no âmbito de cada estado. Entretanto, o uso intencional do advérbio se deve à divulgação de estudos de Oliveira (2010), Araújo (2014) e Castro (2011), que atestam a necessidade de reforma tributária redistributiva em termos territoriais e estratos sociais, como condição para o enfrentamento às desigualdades no financiamento da educação pública.

Tal desigualdade foi agravada pela transferência da responsabilidade da maior parte da oferta da educação básica aos municípios. Refletindo sobre esse processo, Cury afirmava que

A rigor, as políticas de descentralização, sobretudo se acompanhadas do atual modo vigente do pacto federativo, significam um repasse de responsabilidade dos escalões nacionais para os subnacionais. Se estes últimos não forem capazes de sustentar suas responsabilidades, o risco é o de haver um deslocamento do público para o privado e aí reside o risco maior de uma competitividade e seletividade, de corte mercadológico, pouco natural aos fins da educação (Cury, 2001, p. 196).

Além disso, como identificado por Adrião, Borghi e Domiciano (2010), na maior parte das redes públicas cabe aos municípios cumprir o dever do Estado no atendimento às demandas educacionais, que compreende a oferta de creches, pré-escolas e, no mínimo, os cinco primeiros anos do ensino fundamental. Para as autoras,

Paralelamente à ampliação das responsabilidades educativas no âmbito municipal, assiste-se a uma alteração no papel dos governos estaduais e federal, na medida em que assumem a função de monitorar e ou avaliar o desempenho dos alunos das escolas públicas, subtraindo-se, na maioria dos casos, da necessária colaboração técnica e financeira que os governos locais necessitam. Mesmo com a ampliação de recursos federais decorrente do Fundo de Desenvolvimento e Manutenção da Educação Básica (Fundeb) ${ }^{20}$, a maior parte do atendimento à escolaridade básica está sob a responsabilidade municipal (ADRIÃO, BORGHI; DOMICIANO, 2010, p. 286).

Nesses termos, nas regiões mais pobres que concentram os municípios com menor capacidade e autonomia tributária, sem a efetiva participação dos demais entes federados, são significativos os impactos negativos na amplitude do acesso e na qualidade do atendimento.

Segundo Araújo (2012), o regime de colaboração, conforme previsão constitucional, busca o

equilíbrio do desenvolvimento e do bem-estar em âmbito nacional, ou seja, o regime de colaboração para a educação só pode ser regulamentado por Lei complementar, o que requer aprovação no Congresso Nacional por quórum qualificado.[..]Ainda é preciso levar em conta que, estando os fundamentos da Constituição Federal de 1988 ancorados no federalismo cooperativo, a intenção é equilibrar os conflitos federativos e garantir a mesma qualidade de vida para todos os cidadãos, independentemente da região, estado e cidade onde habitam (ARAÚJO, 2012, p. 523, grifo nosso).

A desigualdade no Brasil se expressa em diferenças gritantes, como a verificada em 2011, entre o PIB per capita do município mais rico (Presidente Kennedy - ES, com R \$ 21.632,72, posição mantida até 2017) e do mais pobre da federação (Porangatu - MG, com R \$146,26, substituído 147 vezes por Novo Triunfo - Bahia). Entretanto, de acordo com dados do IBGE, em 2015, dos dez municípios com menor PIB per capita, oito eram maranhenses. O mapa PIB dos Municípios: PIB per capita ${ }^{21}$ explicita a

\footnotetext{
${ }^{20}$ O Fundo de Manutenção e Desenvolvimento da Educação Básica e de Valorização dos Profissionais da Educação - Fundeb foi instituído pela Emenda Constitucional n ${ }^{\circ}$ 53, de 19 de dezembro de 2006 e regulamentado pela Medida Provisória $n^{\circ} 339$, de 28 de dezembro do mesmo ano, convertida na Lei $n^{\circ} 11.494$, de 20 de junho de 2007, e pelos Decretos nº 6.253 e 6.278 , de 13 e 29 de novembro de 2007, respectivamente (FNDE). Disponível em: < https://www.fnde.gov.br/index.php/financiamento/fundeb/sobre-o-plano-ou-programa/sobre-o-fundeb $>$. Acesso em: 10 de out. de 2019.

${ }^{21}$ Disponível em: <https://www.ibge.gov.br/apps/pibmunic/>. Acesso em 9 de jun. de 2019.

Educação em Revista|Belo Horizonte|v.36|e231675|2020
} 
concentração dos municípios mais pobres na região Nordeste, seguido pelos municípios localizados na região da Floresta Amazônica.

Essa desigualdade descomunal também reflete na área educacional, tanto que se estima a taxa de analfabetismo na região nordeste ser quase o dobro da média do país (ARAÚJO, 2016). Nessas condições, apesar da Educação Infantil ser de responsabilidade prioritária dos municípios (Art. 211 da Constituição Federal), é evidente a necessidade de maior participação dos demais entes federados no financiamento e na oferta da educação para crianças de 0 a 6 anos, de modo a possibilitar a realização do direito a esta etapa educacional a quem quer que a demanda.

Os índices apontam que a situação é ainda mais alarmante no atendimento às crianças de zero a 3 anos, conforme verificado nas informações sobre matrículas públicas presentes no gráfico 1, elaborado a partir do período relativo à primeira década de vigência integral da Lei de Responsabilidade Fiscal (Lei Complementar $n^{\circ} 101$, de 4 de mai. 2000).

Tabela 5: Total de estabelecimentos municipais e estaduais que ofertam creche e pré-escola. Maranhão (MA) e Alagoas (AL). Anos selecionados: 2005, 2010, 2015

\begin{tabular}{|c|c|c|c|c|c|c|c|c|c|c|}
\cline { 3 - 13 } \multicolumn{2}{c|}{} & \multicolumn{4}{c|}{$\mathbf{2 0 0 5}$} & \multicolumn{3}{c|}{$\mathbf{2 0 1 0}$} & \multicolumn{3}{c|}{2015} \\
\cline { 3 - 13 } \multicolumn{2}{c|}{} & Estadual & Municipal & Total & Estadual & Municipal & Total & Estadual & Municipal & Total \\
\hline \multirow{2}{*}{ MA } & Creche & 0 & 382 & 382 & 1 & 1153 & 1154 & 3 & 3717 & 3720 \\
\cline { 2 - 13 } & Pré-Escola & 47 & 6673 & 6720 & 21 & 8302 & 8323 & 12 & 7884 & 7896 \\
\hline \multirow{2}{*}{ AL } & Creche & 0 & 152 & 152 & 0 & 252 & 252 & 1 & 531 & 532 \\
\cline { 2 - 13 } & Pré-Escola & 24 & 1428 & 1452 & 18 & 1660 & 1678 & 16 & 1577 & 1593 \\
\hline
\end{tabular}

Fonte: Elaborado pelos autores a partir dos microdados do Censo escolar (INEP/MEC) dos anos de 2005, 2010 e 2015.

Ao considerarmos a oferta direta por parte das redes estaduais, a tabela 5 indica que a quantidade de creches era ínfima em 2015, sendo apenas três no Maranhão e uma em Alagoas. Houve uma diminuição em relação aos estabelecimentos estaduais de pré-escola: no Maranhão, em 2005 havia 47, já em 2015 apenas 12; em Alagoas, no ano 2005 havia 24 e em 2015 o número modificou para 16.

Se o aumento no número de estabelecimentos que ofertam creche foi significativo, suas condições de funcionamento merecem atenção. A tabela 6 , referente às condições de oferta nas creches públicas no estado de Alagoas, ilustra a precariedade desses espaços destinados às crianças pequenas. De acordo com os dados, em 2015 apenas 14,7\% dos estabelecimentos declararam no Censo Escolar ter parque infantil e apenas 27, 8\% tinham pátio descoberto. Mais de $60 \%$ dos estabelecimentos permanecem, desde 2005, sem sanitário adequado às crianças pequenas e 75\% não tinham berçário. Em relação aos serviços de água e esgoto, em 2015 mais de 40\% das creches não eram abastecidas com água encanada. Apenas a alimentação era assegurada a todas as crianças.

Tabela 6: Condições de oferta informadas (Serviços básicos, Infraestrutura geral, Infraestrutura pedagógica, Recursos pedagógicos e assistenciais) - Creches públicas (municipais e estadual) - Alagoas- Anos selecionados: 2005, 2010 e 2015

\begin{tabular}{|l|c|c|c|}
\cline { 2 - 4 } \multicolumn{1}{c|}{} & $\mathbf{2 0 0 5}$ & $\mathbf{2 0 1 0}$ & $\mathbf{2 0 1 5}$ \\
\hline Insumo & \multicolumn{2}{|c|}{ \% de estabelecimentos } \\
\hline Água filtrada consumida pelos alunos & $96,7 \%$ & $96,8 \%$ & $91,2 \%$ \\
\hline Abastecimento de água rede pública & - & $74,2 \%$ & $58,3 \%$ \\
\hline Abastecimento de energia via rede pública & $98,7 \%$ & $100,0 \%$ & $99,2 \%$ \\
\hline Cozinha & $95,4 \%$ & $98,8 \%$ & $99,4 \%$ \\
\hline Sala de leitura & $5,3 \%$ & $10,3 \%$ & $21,4 \%$ \\
\hline Parque infantil & $9,2 \%$ & $15,5 \%$ & $14,7 \%$ \\
\hline Berçário & $18,4 \%$ & $13,1 \%$ & $15,6 \%$ \\
\hline
\end{tabular}

Educação em Revista|Belo Horizonte|v.36|e231675|2020 


\begin{tabular}{|l|c|c|c|} 
Sanitário adequado para Educação Infantil & $32,9 \%$ & $31,7 \%$ & $37,4 \%$ \\
\hline Internet & - & $9,5 \%$ & $34,4 \%$ \\
\hline Alimentação Escolar & $97,4 \%$ & $100 \%$ & $100,0 \%$ \\
\hline Sala de TV & $13,8 \%$ & $72,2 \%$ & $82,5 \%$ \\
\hline Pátio coberto & - & - & $48,9 \%$ \\
\hline Pátio descoberto & - & - & $27,8 \%$ \\
\hline Dormitório & $16,4 \%$ & - & - \\
\hline Brinquedoteca & $1,3 \%$ & - & - \\
\hline Fraldário & $3,3 \%$ & - & - \\
\hline Biblioteca & $2,0 \%$ & - & $11,5 \%$ \\
\hline
\end{tabular}

Fonte: Elaborado pelos autores a partir dos microdados do Censo escolar (INEP/MEC) dos anos de 2005, 2010 e 2015.

O olhar sobre o atendimento aos pequenos no estado de Alagoas é completado pelas informações da tabela 7, referente às condições de oferta da pré-escola. Percebe-se que, em 2015, apenas $5,3 \%$ das instituições apresentavam parque infantil, $29,6 \%$ tinham parque descoberto e um pouco menos da metade $(44,9 \%)$ parque coberto. Os dados também demonstram escassez no que se refere a espaços como biblioteca ou sala de leitura. Ainda que se identifique um incremento nessa década, apenas $12 \%$ das escolas declaram ter biblioteca, enquanto $16,4 \%$ sala de leitura; somente $34,5 \%$ dos estabelecimentos possuíam internet para uso dos alunos. No mesmo ano, apenas 16,6\% das instituições haviam sanitários adequados para a faixa etária das crianças. É alarmante que a porcentagem de estabelecimentos sem acesso a água filtrada para os alunos tenha aumentado entre 2005 e 2015, chegando ao número de 10,3\%.

Tabela 7: Condições de oferta informadas (Serviços básicos, Infraestrutura geral, Infraestrutura pedagógica, Recursos pedagógicos e assistenciais) - pré-escolas públicas (municipais e estadual) - Alagoas- Anos selecionados: 2005, 2010 e 2015

\begin{tabular}{|l|r|r|r|}
\cline { 2 - 4 } \multicolumn{1}{c|}{} & $\mathbf{2 0 0 5}$ & $\mathbf{2 0 1 0}$ & $\mathbf{2 0 1 5}$ \\
\hline Insumo & \multicolumn{2}{|c|}{$\%$ de estabelecimentos } \\
\hline Água filtrada consumida pelos alunos & $95,3 \%$ & $95,4 \%$ & $89,7 \%$ \\
\hline Abastecimento de água rede pública & - & $47,1 \%$ & $48,7 \%$ \\
\hline Abastecimento de energia via rede pública & $92,6 \%$ & $98,3 \%$ & $99,2 \%$ \\
\hline Cozinha & $90,4 \%$ & $97,9 \%$ & $98,7 \%$ \\
\hline Sala de leitura & $5,4 \%$ & $7,4 \%$ & $16,8 \%$ \\
\hline Parque infantil & $2,2 \%$ & $2,6 \%$ & $5,3 \%$ \\
\hline Berçário & $1,2 \%$ & $1,0 \%$ & $3,7 \%$ \\
\hline Sanitário adequado para Educação Infantil & $8,3 \%$ & $6,8 \%$ & $16,6 \%$ \\
\hline Internet & - & $13,5 \%$ & $34,5 \%$ \\
\hline Alimentação Escolar & $99,7 \%$ & $100 \%$ & $100,0 \%$ \\
\hline Sala de TV & $6,7 \%$ & $49,4 \%$ & $74,6 \%$ \\
\hline Pátio coberto & - & - & $44,9 \%$ \\
\hline Pátio descoberto & - & - & $29,6 \%$ \\
\hline Dormitório & $1,3 \%$ & - & - \\
\hline Brinquedoteca & $0,2 \%$ & - & - \\
\hline Fraldário & $0,3 \%$ & - & - \\
\hline Biblioteca & $5,4 \%$ & $8,2 \%$ & $12,2 \%$ \\
\hline
\end{tabular}

Fonte: Elaborado pelos autores a partir dos microdados do Censo escolar (INEP/MEC) dos anos de 2005, 2010 e 2015. 
A tabela 8 apresenta as condições das creches públicas no estado do Maranhão. Segundo o inventário, em 2005, 91,1\% das creches municipais não contavam com parque infantil; situação que piorou nos anos 2010 (96,4\%) e 2015 (96,8\%). Em 2015, apenas 29, 5\% das instituições apresentavam espaços como pátio coberto e 11,4\% pátios descobertos. Uma minoria dispunha de sala de leitura ou biblioteca (4,6\% e 4,7\% respectivamente, no ano de 2015). Mesmo com a maioria das instituições oferecendo alimentação, um número expressivo delas não conta com refeitório. Nem todas as escolas possuíam luz elétrica em 2015 (2\%) e 60\% não eram abastecidas com rede de água pública. Por fim, a respeito da internet, apenas $12 \%$ declaram acesso à rede no ano de 2015.

Tabela 8: Condições de oferta informadas (Serviços básicos, Infraestrutura geral, Infraestrutura pedagógica, Recursos pedagógicos e assistenciais) - creches públicas (municipais e estadual) - Maranhão - Anos selecionados: 2005, 2010 e 2015

\begin{tabular}{|l|c|c|c|}
\multicolumn{1}{l|}{} & $\mathbf{2 0 0 5}$ & $\mathbf{2 0 1 0}$ & $\mathbf{2 0 1 5}$ \\
\hline Insumo & $\mathbf{2}$ de estabelecimentos \\
\hline Água filtrada consumida pelos alunos & $97,6 \%$ & $97,2 \%$ & $89,7 \%$ \\
\hline Abastecimento de água rede pública & - & $43,3 \%$ & $40,3 \%$ \\
\hline Abastecimento de energia via rede pública & - & $93,3 \%$ & $97,3 \%$ \\
\hline Refeitório & $13,9 \%$ & - & $7,2 \%$ \\
\hline Cozinha & - & $85,8 \%$ & $89,7 \%$ \\
\hline Sala de leitura & $2,4 \%$ & $2,5 \%$ & $4,6 \%$ \\
\hline Parque infantil & $8,9 \%$ & $3,6 \%$ & $3,2 \%$ \\
\hline Berçário & $2,4 \%$ & $1,2 \%$ & $2,1 \%$ \\
\hline Sanitário adequado para Educação Infantil & $21,2 \%$ & $8,6 \%$ & $10,6 \%$ \\
\hline Internet & - & $4,1 \%$ & $12,1 \%$ \\
\hline Alimentação Escolar & - & $100 \%$ & $100 \%$ \\
\hline Sala de TV & $3,9 \%$ & $39,7 \%$ & $52,8 \%$ \\
\hline Pátio coberto & - & - & $29,5 \%$ \\
\hline Pátio descoberto & - & - & $11,4 \%$ \\
\hline Dormitório & $2,6 \%$ & - & - \\
\hline Brinquedoteca & $5,5 \%$ & - & - \\
\hline Auditório & $3,9 \%$ & - & - \\
\hline Fraldário & $0,8 \%$ & - & - \\
\hline Biblioteca & $1,0 \%$ & $3,1 \%$ & $4,7 \%$ \\
\hline
\end{tabular}

Fonte: Elaborado pelos autores a partir dos microdados do Censo escolar (INEP/MEC) dos anos de 2005, 2010 e 2015.

Em relação às condições de oferta da pré-escola no estado do Maranhão, os dados demonstram grande escassez nos espaços das instituições. Em 2005 apenas 1\% das unidades possuíam parque infantil, situação que perdurou em 2010. No ano de 2015 houve um aumento irrisório para 1,5\% em instituições escolares com parque infantil. Já em 2015, uma pequena parcela das instituições apresentava espaços como pátio coberto $(23,9 \%)$ ou descoberto $(10,3 \%)$. Tais dados expressam investimento público insuficiente na oferta pública nessa etapa de escolaridade.

A tabela 9 ilustra as condições de oferta informadas por instituições que atendiam crianças de 4 a 6 anos no estado do Maranhão. 
Tabela 9: Condições de oferta informadas (Serviços básicos, Infraestrutura geral, Infraestrutura pedagógica, Recursos pedagógicos e assistenciais) - pré-escolas públicas (municipais e estadual) - Maranhão - Anos selecionados: 2005, 2010 e 2015

\begin{tabular}{|l|c|r|r|}
\cline { 2 - 4 } \multicolumn{1}{c|}{} & $\mathbf{2 0 0 5}$ & $\mathbf{2 0 1 0}$ & $\mathbf{2 0 1 5}$ \\
\hline Insumo & $\mathbf{0}$ de estabelecimentos \\
\hline Água filtrada consumida pelos alunos & - & $96,9 \%$ & $89,4 \%$ \\
\hline Abastecimento de água rede pública & - & $81,8 \%$ & $30,1 \%$ \\
\hline Abastecimento de energia via rede pública & - & $22,2 \%$ & $94,6 \%$ \\
\hline Refeitório & $2,2 \%$ & - & $4,8 \%$ \\
\hline Cozinha & - & $73,2 \%$ & $84,4 \%$ \\
\hline Sala de leitura & - & $1,4 \%$ & $3,5 \%$ \\
\hline Parque infantil & $1,0 \%$ & $1,0 \%$ & $1,5 \%$ \\
\hline Berçário & $0,2 \%$ & $0,1 \%$ & $0,6 \%$ \\
\hline Sanitário adequado para Educação Infantil & $3,8 \%$ & $2,4 \%$ & $6,4 \%$ \\
\hline Internet & - & $3,6 \%$ & $11,1 \%$ \\
\hline Alimentação Escolar & - & $100 \%$ & $100,0 \%$ \\
\hline Sala de TV & $1,3 \%$ & $26,2 \%$ & $45,4 \%$ \\
\hline Pátio coberto & - & - & $23,9 \%$ \\
\hline Pátio descoberto & - & - & $10,3 \%$ \\
\hline Dormitório & $0,2 \%$ & - & - \\
\hline Brinquedoteca & $0,5 \%$ & - & - \\
\hline Auditório & $0,9 \%$ & - & - \\
\hline Fraldário & $0,1 \%$ & - & - \\
\hline Biblioteca & $1,6 \%$ & $2,9 \%$ & $4,4 \%$ \\
\hline
\end{tabular}

Fonte: Elaborado pelos autores a partir dos microdados do Censo escolar (INEP/MEC) dos anos de 2005, 2010 e 2015.

Os dados referentes às condições de oferta informadas pelas instituições públicas de Educação Infantil, tanto do estado do Maranhão como de Alagoas, não apresentavam padrões mínimos expressos nos insumos básicos para um serviço educacional digno. Tal situação exigiria desses governos estaduais uma presença mais direta, que poderia ser realizada por meio de ações de colaboração junto aos municípios para que houvesse uma adequação dos espaços educacionais.

Salienta-se que no período analisado, o Ministério da Educação divulgou o importante documento intitulado Critérios para um Atendimento em Creches que Respeite os Direitos Fundamentais das Crianças (CAMPOS e ROSEMBERG, 2009), no qual há um conjunto de orientações que buscam subsidiar os gestores públicos e os educadores na organização de espaços de atendimentos aos pequenos, respeitando os direitos das crianças a frequentar ambientes seguros, aconchegantes e organizados, assegurando o cuidado e o direito à educação.

\section{NOTAS SOBRE A PARTICIPAÇÃO DOS GOVERNOS ESTADUAIS DE ALAGOAS E MARANHÃO NO FINANCIAMENTO DA EDUCAÇÃO INFANTIL}

A partir de 2006, considerando o art. $212^{22}$ da CF-88 que versa sobre as receitas vinculadas de cada ente federado destinadas à Manutenção e Desenvolvimento do Ensino (MDE), o então ministro

\footnotetext{
${ }^{22}$ Art. 212. A União aplicará, anualmente, nunca menos de dezoito, e os Estados, o Distrito Federal e os Municípios vinte e cinco por cento, no mínimo, da receita resultante de impostos, compreendida a proveniente de transferências, na manutenção e desenvolvimento do ensino. (BRASIL, 1988). 
da educação Fernando Haddad, por meio da portaria no 06/2006 do MEC instituiu o Sistema de Informações sobre Orçamentos Públicos em Educação - SIOPE, que tinha como objetivo

\begin{abstract}
gerar base de dados nacional detalhada e confiável sobre a aplicação da receita vinculada à manutenção e ao desenvolvimento do ensino; II. assegurar transparência, publicidade e efetividade ao controle público da aplicação constitucional mínima em educação; III. disponibilizar ferramenta de auxílio aos órgãos de controle interno e externo da Administração Pública; IV. subsidiar a elaboração de políticas educacionais em todos os níveis de Governo; V. produzir indicadores de eficiência e eficácia da despesa pública em educação (MEC, 2006).
\end{abstract}

Tendo por base as informações disponíveis relativas aos Estados em análise no sitio eletrônico do SIOPE, foram inventariados os valores contidos nos seguintes relatórios: Relatório Resumido da Execução Orçamentária - RREO - Anexo VIII da Lei de Responsabilidade Fiscal (a partir de 2006); Demonstrativo de receitas e despesas com MDE (somente em 2005); Demonstrativo da função educação; Quadro Resumo de Despesas. A partir das informações inventariadas e atualizadas pelo Índice Nacional de Preços ao Consumidor (INPC) em julho de 2018, verificou-se o volume dos recursos previstos para Manutenção e Desenvolvimento de Ensino direcionados ao setor privado por meio de aplicações em duas categorias econômicas, selecionadas em pesquisa (ADRIÃO (coord.); DOMICIANO; 2016) que considerou os mecanismos mais frequentemente adotados pelos governos subnacionais para repasse dos recursos de MDE para o setor privado:

3.33.90.39 - Outros Serviços de Terceiros - Pessoa Jurídica englobando despesas

orçamentárias decorrentes da prestação de serviços por pessoas jurídicas para órgãos públicos, tais como: assinaturas de jornais e periódicos; tarifas de energia elétrica, gás, água e esgoto; serviços de comunicação (telefone, telex, correios, etc.); fretes e carretos; locação de imóveis (inclusive despesas de condomínio e tributos à conta do locatário, quando previstos no contrato de locação); locação de equipamentos e materiais permanentes; software; conservação e adaptação de bens imóveis; seguros em geral (exceto os decorrentes de obrigação patronal); serviços de asseio e higiene; serviços de divulgação, impressão, encadernação e emolduramento; serviços funerários; despesas com congressos, simpósios, conferências ou exposições; valerefeição; auxílio-creche (exclusive a indenização a servidor); habilitação de telefonia fixa e móvel celular; e outros congêneres, bem como os encargos resultantes do pagamento com atraso de obrigações não tributárias (BRASIL, 2017, p. 70).

3.33.50.00 - Transferências às Instituições Privadas Sem Fins Lucrativos "despesas orçamentárias realizadas mediante transferência de recursos financeiros a entidades sem fins lucrativos que não tenham vínculo com a administração pública" (BRASIL, 2017, p. 61).

A fim de verificar o repasse de verba pública para o setor privado, analisou-se os valores repassados pelos governos para as categorias econômicas selecionadas, tendo em vista o montante total gasto em MDE anualmente na subfunção Educação Infantil declarado pelos estados. Define-se como gasto total na subfunção Educação Infantil os valores disponíveis nos relatórios, para o ano de 2005, no quadro "Despesas com Aplicação em Manutenção e Desenvolvimento do Ensino (MDE) + FUNDEF" que integra os "Demonstrativos de Receitas e Despesas com MDE Segundo Subfunções (Níveis De Ensino)" e, a partir de 2006, os valores disponíveis em "Manutenção e Desenvolvimento Do Ensino Despesas Custeadas Com a Receita Resultante de Impostos e Recursos do FUNDEB" do RREO de cada ano.

Como visto no item 1 desse trabalho, a rede pública de Alagoas, mais precisamente a municipal, concentra o maior número de matrículas na Educação Infantil. Comparando os dados de matrículas de creche e pré-escola, observa-se no gráfico 6 que, partir de 2009, as matrículas nas creches crescem, enquanto as matrículas na pré-escola, após três anos, sofrem uma relativa estagnação. Na prática

Disponível em: < https://www.senado.leg.br/atividade/const/con1988/con1988_15.12.2016/art_212_asp> Acesso em: 10 de ago. de 2019 
o atendimento público à educação infantil é ampliado sem a presença direta da oferta pelo governo estadual.

\section{Gráfico 6: Tendência das matrículas públicas da Educação Infantil no estado de Alagoas}

(2005-2015)

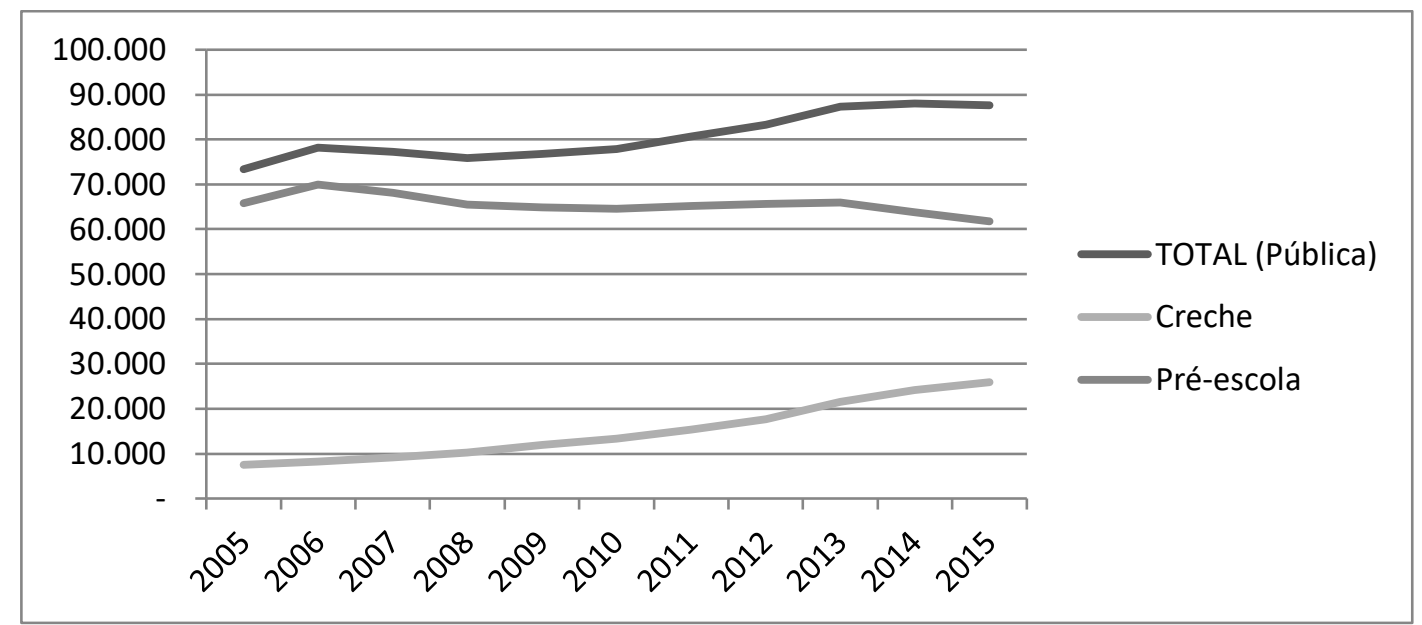

Fonte: autores com base em dados da pesquisa ADRIÃO (coord.); DOMICIANO; 2016.

Considerando que a cooperação entre o estado de Alagoas e os municípios que o integram poderia correr pela destinação de recursos orçamentários na subfunção Educação Infantil, o gráfico 7 capta, para o período em que os dados estavam disponíveis, o "comportamento" desta opção pelas gestões governamentais. Em 2005 (governo do PSB) não houve repasse de MDE para essa etapa da escolaridade por pare do governo estadual aos municípios. No ano de 2006 (governo do PDT) a destinação de recurso para a educação infantil representou 0,0020\% do total gasto de MDE pelo estado no mesmo ano. Já em 2007 (governo PSDB) houve novamente repasse para o Educação Infantil por parte do estado, representando apenas 0,0024\% do total gasto de MDE pelo governo de Alagoas no mesmo ano. Porém, novamente nos anos de 2008 e 2009 (ainda governos do PSDB), não há registro de repasse de verba de MDE para a etapa da educação Infantil. Em 2010, primeiro ano de composição integral do FUNDEB, ainda sobre o governo de Teotônio Viela Filho do PSDB, assiste-se a um pico de gasto da ordem de zero de gastos em 2009 para $\mathrm{R} \$$ 68.875,95 em 2010 e $\mathrm{R} \$ 992.857,70$ em 2011, o qual decai consecutivamente até 2013. Nos últimos dois anos do período pesquisado, 2014 e 2015, o estado de Alagoas, sob o governo de Renan Calheiros do MDB (a partir de $1^{\circ}$ de janeiro de 2015), não divulgou os dados de receitas e investimentos em educação por meio do SIOPE.

\section{Gráfico 7: Gasto total em MDE na Educação Infantil no Estado de Alagoas (2005-2013)}

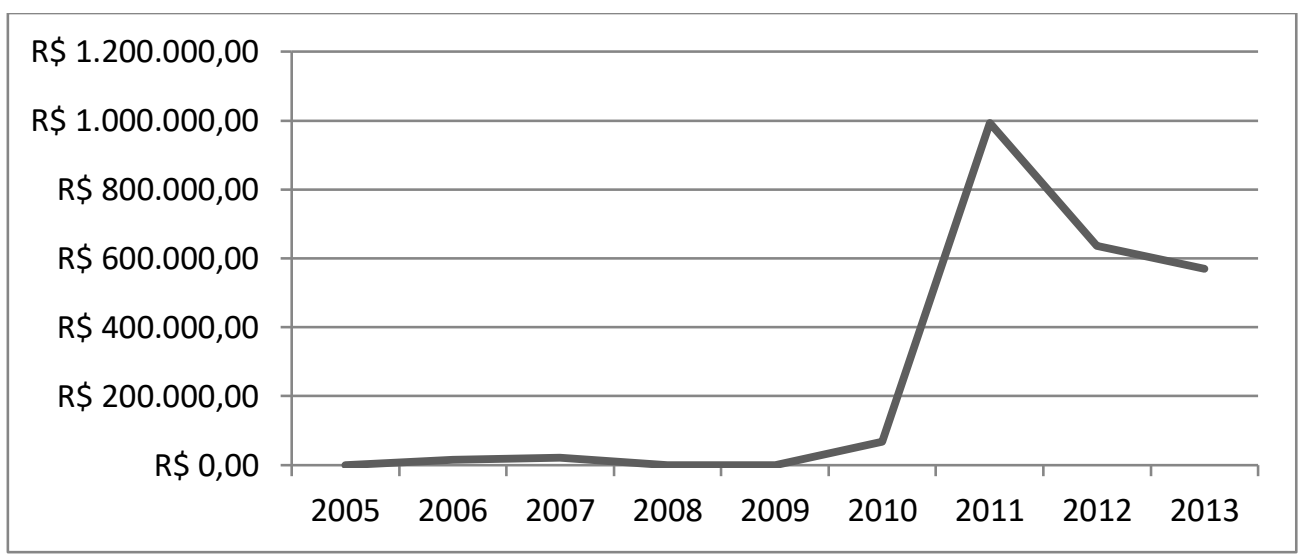

Fonte: autores com base em dados da pesquisa ADRIÃO (coord.); DOMICIANO; 2016. 
Por outro lado, o gráfico 8 apresenta dois picos, em que houve, de maneira proporcional ao total gasto com educação infantil pelo estado nos mesmos anos, maior gasto destinado esfera privada, nos anos de 2007 e 2010. Do total gasto com a educação infantil realizado por Alagoas em 2007 (algo em torno de 22.431,01 em valores corrigidos para 2018), 100\% do valor foi registrado na categoria econômica 3.33.90.39. Dessa forma, o estado gastou toda a verba de MDE que destinou para Educação infantil com Serviços de Terceiros e Pessoas Jurídicas no ano 2007. Já em 2010 o estado registrou 29,78\%, dos gastos de MDE destinados à educação infantil, o valor nominal (também corrigido para 2018) foi de R\$ 20.512,88, novamente na categoria econômica referente a Serviço de Terceiros e Pessoas Jurídica, seguindo de $\mathrm{R} \$ 23.451,38$ em 2012 e 22.980,35 em 2013 (23,71\% e 22,98\%, respectivamente).

\section{Gráfico 8: Percentual de gasto registrado nas categorias econômicas selecionadas em relação ao gasto total com Educação Infantil no estado de Alagoas (2005-2013)}

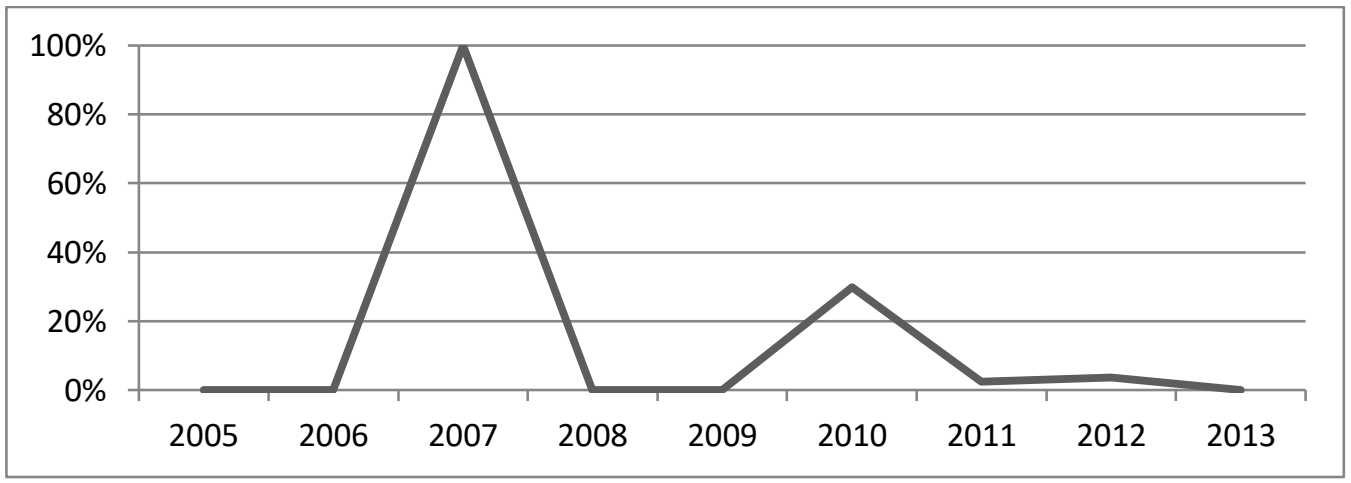

Fonte: autores com base em dados da pesquisa ADRIÃO (coord.); DOMICIANO; 2016.

Durante toda a série histórica analisada somente no ano de 2011 registrou-se na categoria econômica 3.33.50.00, representando 2,39\% dos gastos totais com a educação infantil pelo estado de Alagoas. Em valores nominais corrigidos pelo INPC de julho de 2018, o valor é de R $\$ 265,57$ transferido às instituições privadas sem fins lucrativos.

O estado do Maranhão segue a mesma tendência de Alagoas na oferta pública, com aumento do atendimento de 0 a 3 anos e diminuição da pré-escola, a qual apresentou queda acentuada a partir de 2010, como demonstrado no gráfico 9. Contraditoriamente, nesse mesmo ano, ocorre um "pico" nos gastos totais em MDE com a educação infantil por parte do estado. (gráfico 10)

\section{Gráfico 9: Tendência das matrículas públicas da Educação Infantil no estado do Maranhão}

(2005-2015)

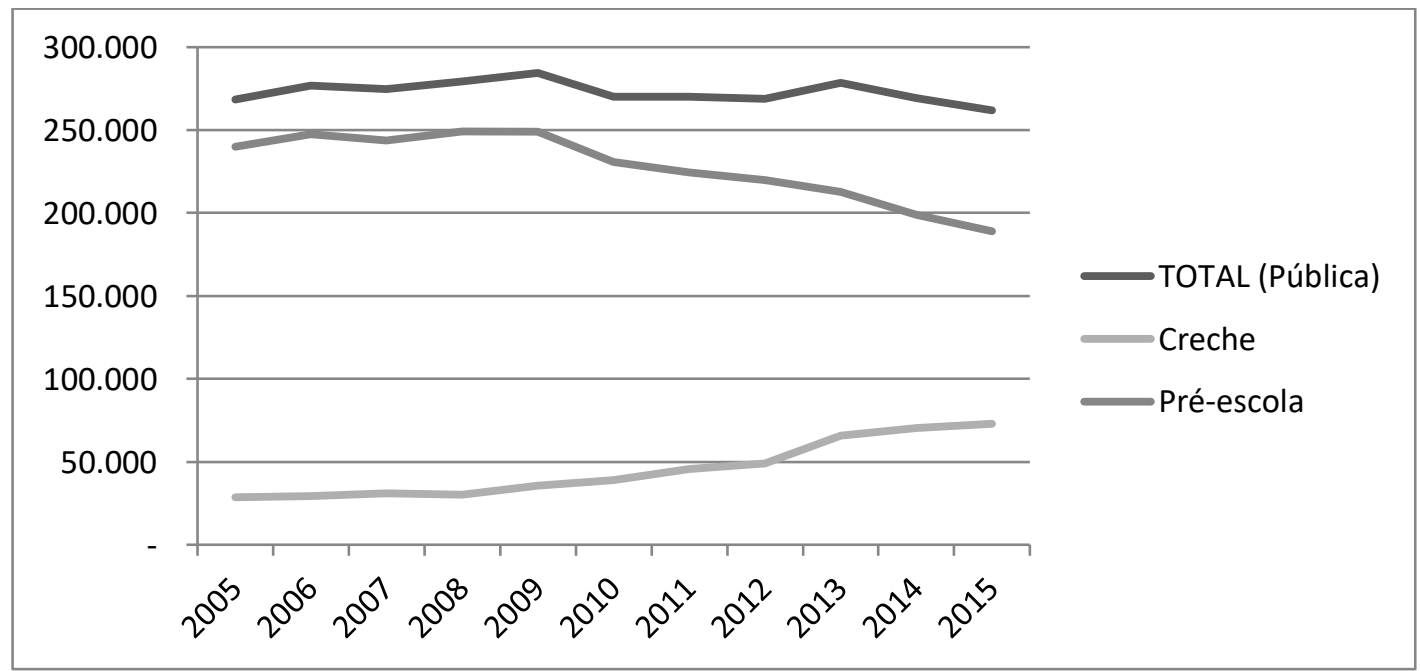


Fonte: autores com base em dados da pesquisa ADRIÃO (coord.); DOMICIANO; 2016.

Em 2010 há um acréscimo dos gastos totais em educação infantil, ano em que também se observou um acréscimo de aproximadamente $12 \%$ de matrículas públicas no atendimento de crianças de 0 a 3 anos. Entretanto, do total gasto em MDE com educação infantil, 15\% foram registrados nas categorias econômicas referentes ao setor privado.

Gráfico 10: Gasto total governo estadual em MDE na Educação Infantil - Maranhão (20052015)

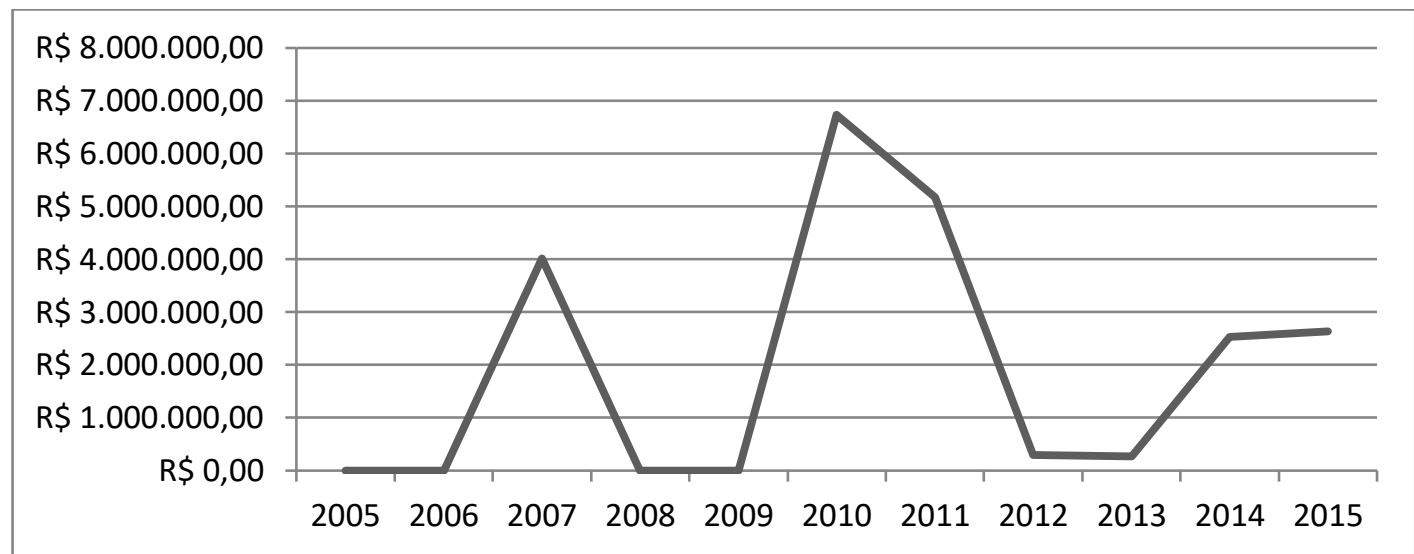

Fonte: autores com base em dados da pesquisa ADRIÃO (coord.); DOMICIANO; 2016.

Conforme observado no gráfico 11, em 2012 e 2013, o Estado do Maranhão registrou 100\% dos recursos em MDE destinados para educação infantil, na categoria econômica 3.33.90.39 - Outros Serviços de Terceiros - Pessoa Jurídica, representando um valor de $\mathrm{R} \$ 295.662,34$ no ano de 2012 e R \$ 272.056,57, em 2013. Os dados divulgados apontam que as maiores taxas destinadas ao setor privado ocorreram na gestão da governadora Roseana Sarney.

Gráfico 11: Percentual de gasto na categoria econômica 3.33.90.39 - Outros Serviços de Terceiros - Pessoa Jurídica no estado do Maranhão (2005-2015)

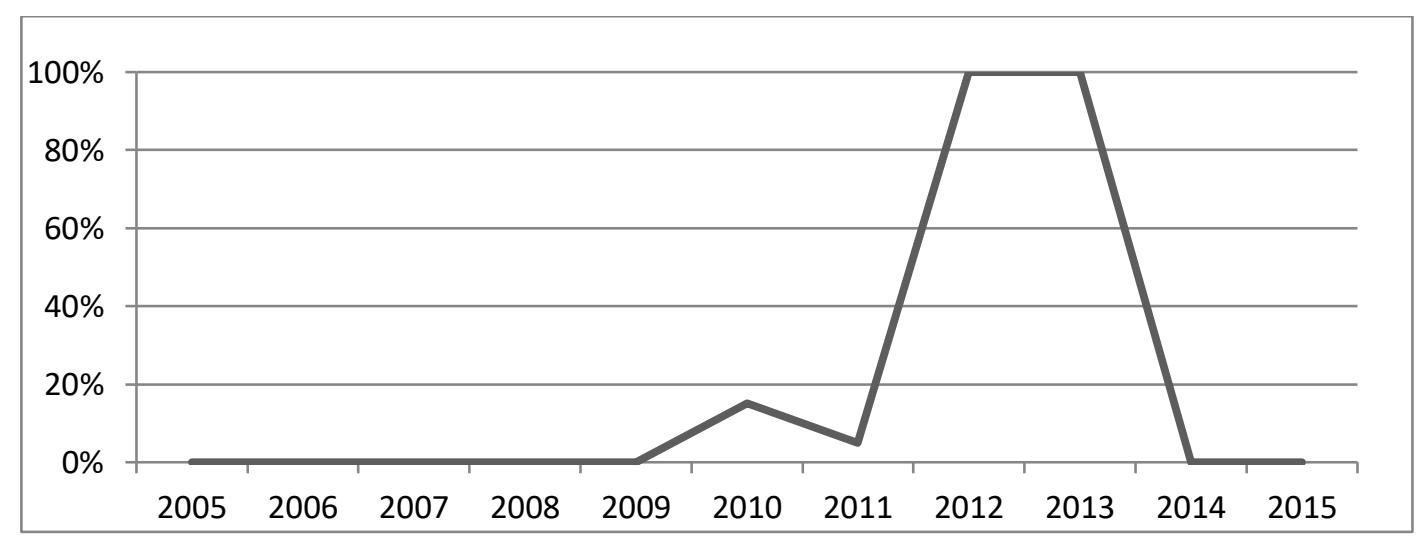

Fonte: os autores com base em dados da pesquisa ADRIÃO (coord.); DOMICIANO; 2016.

Em toda a série histórica estudada, não houve registro de gastos na categoria econômica 3.33.50.00 - Transferência a Instituição Privada Sem Fins Lucrativos. Observa-se que a proporção da oferta pública demonstrou aumento a partir de 2007, chegando a $82 \%$ das matrículas totais no mesmo ano. A variação das matrículas públicas no período é de aproximadamente $4 \%$, transitando de $75 \%$ no ano 2005 para 79\% em 2015. Apesar dos dados positivos em relação à tendência das matrículas no estado, os dados mostram que ainda há diminuição e pouca participação do governo estadual em relação aos 
gastos em MDE na educação infantil; tornando alarmante a qualidade em que isso é oferecido, principalmente no atendimento de 0 a 3 anos.

Em síntese, no período de dez anos de vigência da lei de reponsabilidade Fiscal e mesmo antes da introdução do chamado novo regime fiscal decorrente da Emenda Constitucional 95 do ano de 2016, observa-se que os governos estaduais do Maranhão e Alagoas, salvo em anos específicos, não colaboraram à diminuição das desigualdades no atendimento educacional às crianças pequenas. Considerando-se a enorme taxa de municipalização da educação, Maranhão foi um dos primeiros estados a descentralizar o atendimento da educação obrigatória para os municípios (ARELARO e BARRETTO, 1985) situação que, em 2015 , se expressava na concentração de $78,56 \%$ das matrículas da educação infantil em redes municipais, $0,04 \%$ na rede estadual e $21,39 \%$ em instituições privadas. Já no caso de Alagoas, os municípios respondem por $75,39 \%$ das matrículas da educação infantil, o estado $0,28 \%$ e as redes privadas $24,33 \%$, no último ano do período estudado. Recordando que os municípios mais pobres do país se encontravam nos dois estados, a ausência do governo estadual no suporte ao atendimento dos pequenos é fator de cristalização do precário cenário apresentado.

\section{CONSIDERAÇÕES FINAIS}

Esse estudo evidenciou-se a necessidade da efetivação do regime de colaboração (previsto no Art. 211 da CF 88 e modificada pela emenda constitucional n¹4, de 12 de setembro de 1996) nas regiões mais pobres. Em Alagoas e Maranhão, a esfera estadual foi gradativamente extinguindo as matrículas na pré-escola e pouco participou da oferta direta no atendimento nas creches. Mesmo com aumento nas matrículas no atendimento de crianças de 0 a 3 anos em ambos os estados, a demanda não atendida ilustra a dificuldade dos municípios em atingir a Meta 1 do PNE (2011).

A tabela 10 ilustra o aumento da oferta na educação infantil, e embora compreende-se que com os dados disponíveis não é possível averiguar os impactos do PNE (2011) na Educação Infantil nos estados estudados, assim como não é possível observar os impactos do PNE (2001), indica-se que os dois estados, ainda estavam distantes em 2017 de atingirem a meta 1 do PNE (2011), na qual se prevê a universalização da pré-escola e atendimento de no mínimo $50 \%$ nas creches.

Tabela 10: Taxa de escolarização dos estados de Alagoas e Maranhão (2016 e 2017)

\begin{tabular}{cccc} 
UF & ETAPA & $\mathbf{2 0 1 6}$ & $\mathbf{2 0 1 7}$ \\
\hline \multirow{2}{*}{ Alagoas } & Creche & $24,30 \%$ & $23,60 \%$ \\
& Pré-escola & $86,80 \%$ & $89,10 \%$ \\
\hline \multirow{2}{*}{ Maranhão } & Creche & $27,30 \%$ & $28 \%$ \\
& Pré-escola & $96,90 \%$ & $96,30 \%$ \\
\hline
\end{tabular}

Fonte: IBGE/PNADC 2016-2017 - Educação.

Em Alagoas, no período de maior destinação de recursos em MDE para o setor privado (100\% no ano de 2007 e 30\% em 2010), ocorreu a diminuição da oferta pública da pré-escola e aumento das matrículas municipais no atendimento em creche, em relação ao ano anterior. Em 2010, na pré-escola houve um aumento na rede privada e uma diminuição das matrículas públicas, nas esferas estadual e municipal. O estado demonstra ausência da transparência na divulgação dos dados nos dois últimos anos pesquisados e, também, não há divulgação dos gastos totais na subfunção nos anos de 2005, 2008 e 2009. Os gastos nas categorias econômicas elencadas foram publicados apenas em quatro anos do período analisado.

No estado do Maranhão, em 2012 e 2013 o montante total dos recursos públicos na subfunção foi direcionado ao setor privado. Nesse período, aumentou-se a oferta pública e privada no atendimento de crianças de 0 a 3 anos e diminuição das matrículas na pré-escola nas duas esferas. $\mathrm{Na}$ mesma tendência em relação às matrículas, em 2010, ano em que houve maior gasto total em MDE na 
subfunção, cerca de 15\% dos gastos totais foram destinados à esfera privada. O estado divulgou os gastos nas categorias econômicas apenas entre 2010 e 2013.

Percebe-se que nos anos destacados (2012 e 2013 no Maranhão e 2007 em Alagoas) os governos estaduais incidiram no financiamento da Educação Infantil somente por meio da transferência de verba pública para setor privado, via repasse para a categoria econômica 3.33.90.39 - Outros Serviços de Terceiros - Pessoa Jurídica, deixando os demais gastos a cargo das prefeituras. A opção dos governos estaduais parece indicar uma priorização de repasse dos fundos públicos para o setor privado. Contudo, vale destacar que tais fundos, em determinados anos, desaparecem dos registros do SIOPE, ou seja, há períodos em que se lança zero gastos nessa categoria econômica.

O estudo aqui apresentado evidenciou, ainda, que não há praticamente registro na categoria econômica 3.33.50.00 - Transferências a Instituições Privadas sem fins lucrativos para ambos os estados. A única exceção ocorreu em 2011 no estado de Alagoas, quando registrou R \$265,57 (valores corrigidos pelo INPC em julho de 2018); importância irrisória para o orçamento público de um estado em uma determina categoria econômica.

Além do número de matrículas, considera-se em quais condições a educação infantil foi ofertada. Torna-se relevante analisar, no âmbito do regime de colaboração, a participação dos estados no investimento dessa etapa de escolaridade, bem como a destinação dos gastos em Manutenção e Desenvolvimento de Ensino. Já que a participação dos governos estaduais na oferta direta do atendimento de crianças de 0 a 6 anos é baixa ou inexistente e, assim, demanda aos municípios a maior parte das matrículas;

$\mathrm{Na}$ medida em que a educação infantil requer um maior investimento em relação às demais etapas da educação básica e que a expansão de suas vagas, ao minimizar a responsabilidade do Estado com menor custo e qualidade, apresenta estreita relação com a ampliação de convênios entre os governos subnacionais e instituições privadas, ocorre que as crianças de regiões mais vulneráveis, principalmente de 0 a 3 anos, sejam mais prejudicadas (BARBOSA \& ADRIÃO, 2016; FLORES \& PERONI, 2018). Tal afirmativa ressalta a importância da manutenção do regime de colaboração no financiamento da educação nas regiões mais pobres, a fim de garantir o direito constitucional à educação com qualidade.

Vale lembrar que o estudo focou nos gastos de MDE para tratar do financiamento público da educação infantil pelos estados, porém isso não significa que existe apenas essa forma de subsídio do estado para o regime de colaboração. Destaca-se como alternativas, por exemplo, os empréstimos de prédios, repasse do salário educação, projetos e programas que não aparecem no gasto de MDE.

Dessa maneira, a análise aqui apresentada, de natureza exploratória, indica a necessidade de pesquisas futuras, com o objetivo de qualificar, concretamente, a utilização dos recursos públicos nas esferas privadas.

\section{REFERÊNCIAS}

ADRIÃO, T. A privatização dos processos pedagógicos: Grupos editoriais e os negócios na educação básica. In: MARINGONI, G. (org). O negócio da Educação. São Paulo: Olho D’água e Fapesp. 2017(a). p. 129-144.

ADRIÃO, T. (coord.); DOMICIANO, C. Gastos estaduais de MDE realizados com o setor privado (2005-2015). Campinas, 2016. Não publicado.

ADRIÃO, T.; DOMICIANO, C. A Educação Pública e as Corporações. Revista de Financiamento da Educação, Porto Alegre, v. 8, n. 3, 2018, p. 01-17. Disponível em: <https://seer.ufrgs.br/fineduca/article/viewFile/79084/47919>. Acesso em: 22 de out. 2019

ADRIÃO, T. e GARCIA, T. (Org.). CURRÍCULO, GESTÃo E OFERTA DA EDUCAÇÃO BÁSICA BRASILEIRA: incidências de atores privados nos sistemas estaduais (2005-2015). Coleção estudos sobre a privatização da educação no Brasil. Curitiba: CRV, 2018. 
Disponível em <https://editoracrv.com.br/produtos/detalhes/33565-crv>. Acesso em: 21 de out. 2019

ADRIÃO, T.; BORGHI, R.; DOMICIANO, C. A.. Educação Infantil, ensino fundamental: inúmeras tendências de privatização. Retratos da Escola, Brasília, v. 4, n. 7, p. 285-297, 2010.

ALAGOAS. Secretaria de Estado da Educação. Plano Estadual de Alagoas (2015-2015). Alagoas: Maceió, 2015.

ALVES, T; PASSADOR, C. S.; Educação pública no Brasil: a origem socioeconômica dos alunos e as condições de oferta de ensino no contexto da avaliação da educação básica. São Paulo: Annablume, 2011.

ALVES, T.; SILVEIRA, A. D.; SCHNEIDER, G.; DIDONET, M. Laboratório de Dados Educacionais. Disponível em: < https://dadoseducacionais.c3sl.ufpr.br/\#/>. Acesso em: 01 jun. 2019.

ARAÚJO, G. C. Federalismo cooperativo e arranjos de desenvolvimento da educação: o atalho silencioso do empresariado para a definição e regulamentação do regime de cooperação. RBPAE - v. 28, n. 2, p. 515-531 mai/ago. 2012

ARAÚJO, L. O CAQi e o novo papel da União no financiamento da Educação Básica. Jundiaí: Paco Editorial, 2016.

ARAÚJO, L. O desafio do regime de colaboração no novo Plano Nacional de Educação. JORNAL DE POLÍTICAS EDUCACIONAIS, Curitiba, v. 16, p. 59-65, jul.-dez. de 2014.

ARELARO, L. A não-transparência nas relações público- privadas: o caso das creches conveniadas. In: ADRIÃO, T.; PERONI, V. (org.). Público e Privado na Educação: novos elementos para o debate, São Paulo: Xamã, 2008, v. 1, p. 51-66

ARELARO, L. R. G.; BARRETTO, E. S. S.. A municipalização do ensino de $1^{\circ}$ grau: tese controvertida. Revista da Faculdade de Educação - FEUSP, São Paulo, v. 11, p. 193-210, 1985.

BARBOSA, L. M. R.; ADRIÃO, T. M. F.. Atuação dos governos estaduais na efetivação do acesso à Educação Infantil: tema para o debate. Revista de Educação Movimento, Universidade Federal Fluminense, ano 2016, n. 5, p. 176-195

BRASIL. Lei 13.005, de 25 de junho de 2014. Aprova o Plano Nacional de Educação (PNE) e dá outras providências. Diário Oficial da União [da] República Federativa do Brasil: Brasília, 26 jun. 2014.

BRASIL. Fundo Nacional de Desenvolvimento da Educação. SIOPE: Relatórios Estaduais (20052015).

Disponível em: <http://www.fnde.gov.br/fnde_sistemas/siope/relatorios/relatorios-estaduais $>$. Acesso em: 10 de ago. de 2019.

BRASIL. Constituição da República Federativa do Brasil. Diário Oficial da República Federativa do Brasil, Brasília, 05 de out. de 1988.

BRASIL. Emenda Constitucional no. 14, de 12/09/1996 regulamentada pela Lei no 11.494/07. Publicada no DOU em 13 de set. de 1996.

BRASIL. Emenda Constitucional n ${ }^{\mathbf{0}}$.59, de 11/11/2009. Publicada no DOU em 12 de nov. de 2009. 
BRASIL. Lei $\mathbf{n}^{0}$ 9.394, de 20 de dezembro de 1996. Estabelece as diretrizes e bases da educação nacional. Diário Oficial da União. Brasília, 23 de dez. de 1996.

BRASIL. Lei Complementar n⿳0 101, de 04 de maio de 2000. Lei de Responsabilidade Fiscal.

BRASIL. Ministério do Planejamento, Desenvolvimento e Gestão. Secretaria de Orçamento Federal. Manual técnico de orçamento MTO. Edição 2017. Brasília, 2016. 159 p.

Disponível em: <http://www.orcamentofederal.gov.br/informacoes-orcamentarias/manualtecnico/mto_2017-1a-edicao-versao-de-06-07-16.pdf.> Acesso em: 01 jun. 2019.

CAMPOS, M. M. et al. Creche e Pré-escola no Brasil. 4. ed. São Paulo: Cortez; Fundação Carlos Chagas, 2006.

CAMPOS, M. M. e ROSEMBERG, F. Critérios para um atendimento em creches que respeite os Direitos fundamentais das crianças. Brasília: MEC, SEB, 2009.

Disponível em: < http://portal.mec.gov.br/dmdocuments/direitosfundamentais.pdf>. Acesso em: 08 de out. de 2019

CASTRO, J. A. Financiamento da Educação Pública no Brasil: evolução dos gastos. In: GOUVEIA, A. B; PINTO, J. M.; CORBUCCI, P. R. (Org.). Federalismo e Políticas Educacionais na

Efetivação do Direito à Educação no Brasil. Brasília: Ipea, 2011. Disponível em:

$<$ http://repositorio.ipea.gov.br/bitstream/11058/8437/1/Financiamento \%20da\%20educa \%c3\%a7\%c

3\%a3o $\% 20 \mathrm{p} \%$ c3\%bablica $\% 20$ no $\% 20$ Brasil_evolu $\%$ c3\%a7\%c3\%a3o $\% 20$ dos $\% 20$ gastos.pdf $>$. Acesso

21 de set. de 2019.

CÔRREA, B. C. Políticas de educação infantil no Brasil: ensaio sobre os desafios para a concretização de um direito. Jornal de Políticas Educacionais, Curitiba, n. 9, p. 20-29, jan./jun. 2011b.

Disponível em: <https://revistas.ufpr.br/jpe/article/view/25172/16820>. Acesso em: 10 de julho de 2019

CURY, C. R. J.. A Educação Básica no Brasil. Educação e Sociedade, Campinas, v. 23, n. 80, p. 168200, set. 2002.

DIDONET, V.. A educação infantil na educação básica e o Fundeb. In: LIMA, M.J.R.; DIDONET, V. (Org.). FUNDEB: avanços na universalização da educação básica. Brasília: INEP, 2006. p. 31-48.

FLORES, M. L.; PERONI, V. M. V. Políticas públicas para a educação infantil no Brasil: desafios à consolidação do direito no contexto emergente da nova filantropia. Roteiro, Joaçaba, v. 43, n. 1, p. 133154, jan/abr 2018.

MARANHÃO (Estado). Lei n ${ }^{\mathbf{1}} \mathbf{1 0 . 0 9 9}$, de 11 de junho de 2014. Secretaria de Estado da Educação. Plano Estadual de Educação do Estado do Maranhão (SUPLEMENTO). Diário Oficial do estado do Maranhão: Poder Executivo, São Luis (MA), ano 108, n 111, p. 1-30, 11 de jun. 2014.

Disponível em: <http://www.educacao.ma.gov.br/files/2016/05/suplemento_lei-10099-11-06-2014PEE.pdf>. Acesso em: 05 de out. 2019.

OLIVEIRA, R. L. P.; SANTANA, W. (Orgs.). Educação e federalismo no Brasil: combater as desigualdades, garantir a diversidade. Brasília: Unesco, 2010.

PINTO, J. M. R.. A política recente de fundos para o financiamento da educação e seus efeitos no pacto federativo. Educação \& Sociedade, Campinas, v. 28, n. 100, p. 877-897, 2007. 
PINTO, J. M. de R.. Financiamento da educação básica. - A divisão de responsabilidades. Revista Retratos da Escola, Brasília, v. 6, n. 10, p. 155-172, jan./jun. 2012. Disponível em: $<$ http//www.esforce.org.br>. Acesso em: 09 de out. 2019.

SAMPAIO, G. T. C.; OLIVEIRA, R. L. P.. Dimensões da desigualdade educacional no Brasil. Revista Brasileira de Política e Administração da Educação - Periódico científico editado pela ANPAE, Porto Alegre, v. 31, n. 3, p. 511-530, jun. 2015.

Disponível em: <http://seer.ufrgs.br/index.php/rbpae/article/view/60121/37016>. Acesso em: 15 de out. 2019

TEIXEIRA, A.. Educação é um direito. São Paulo: Companhia Editora Nacional, 1968.

VETTORAZZO, L. .20 Estados tiveram renda per capita abaixo da média de R $\$ 1.226$ em 2016. Folha de S. Paulo. São Paulo, 24 fev. 2017. p. 1-1. Disponível em: https://www1.folha.uol.com.br/mercado/2017/02/1861675-20-estados-tiveram-renda-per-capitaabaixo-da-media-em-2016-diz-ibge.shtml. Acesso em: 20 maio 2018.

Submetido: 02/12/2019

Aprovado: $12 / 06 / 2020$

ERRATA

DOI: http://dx.doi.org/10.1590/0102-4698231675er

Para o artigo publicado e citado como:

LOPES, NICANOR M., ADRIÃO, THERESA, \& RAMOS, GABRIELA CRISTINA. (2020). ATUAÇÃO DOS GOVERNOS DOS ESTADOS DE ALAGOAS E MARANHÃO NO FINANCIAMENTO DA EDUCAÇÃO INFANTIL. Educação em Revista, 36, e231675. Epub October 16, 2020.https://doi.org/10.1590/0102-4698231675

No conteúdo em PDF consta a duplicidade da numeração do gráfico 1. Portanto, em todo o texto, exceto para o primeiro gráfico, a numeração fica aumentada em uma unidade, como especificado a seguir:

Para a segunda citação de gráfico 1

considere gráfico 2

No texto e no título, onde consta gráfico 2 ,

Leia-se gráfico 3, ficando como segue:

Os gráficos 2 e 3 mostram que, em todo o período, houve predomínio de matrículas da educação infantil (creche e pré-escola) nas redes públicas, com explicito predomínio das matrículas municipais. No caso do atendimento de crianças de 0 a 3 anos (gráfico 2), nesse período, as matrículas aumentaram na rede pública e privada concomitantemente e de maneira significativa, sendo a taxa de crescimento de 245,23 $\%$ na rede pública e $191,40 \%$ na privada.

\section{Gráfico 2: Matrícula públicas, municipais e privadas- CRECHE / Alagoas (2005-2015)}

Já na pré-escola (gráfico 3), a matrícula total oscilou pouco, mas indicou uma diminuição de 6,23\% da oferta pública entre 2005 e 2015, ainda que tenha sido ampliada no ano de 2006. Paralelamente, a partir 
de 2010, observa-se um aumento significativo na oferta privada da pré-escola gerando um aumento de $27,11 \%$ nas matrículas privadas.

Gráfico 3: Matrícula públicas/municipais e privadas. PRE- ESCOLA- Alagoas (2005-2015)

No texto e no título, onde consta gráfico 3,

Leia-se gráfico 4, ficando como segue:

O gráfico 4 ilustra o aumento expressivo no total de matrículas em creches entre os anos de 2005 e 2015.

Gráfico 4: Tendências das matrículas públicas/ municipais e privadas em creches no estado do Maranhão (2005-2015)

No texto e no título, onde consta gráfico 4,

Leia-se gráfico 5, ficando como segue:

Já em relação à Pré-escola, o gráfico 5 mostra o decréscimo de 21,4\% no atendimento pelas redes públicas e de $38,26 \%$ na rede privada para alunos de 4 a 6 anos.

Gráfico 5: Tendências das Matrículas públicas/municipais e privadas em pré-escola no estado do Maranhão (2005-2015)

No texto e no título, onde consta gráfico 5 ,

Leia-se gráfico 6, ficando como segue:

Em síntese, em ambos e independentemente do partido que capitaneia o executivo, a presença do governo estadual na oferta de vagas para a educação infantil é inicialmente marginal e tende a ser nula. Essa ausência é agravada quando se observa o percentual da população na faixa etária correspondente, a quem não estava assegurado o acesso ao atendimento educacional, como indicado no gráfico 6.

Gráfico 6: Taxa de matrícula líquida nos estados do Maranhão e Alagoas - anos selecionados disponíveis

No texto e no título, onde consta gráfico 6,

Leia-se gráfico 7, ficando como segue:

Comparando os dados de matrículas de creche e pré-escola, observa-se no gráfico 7 que, partir de 2009, as matrículas nas creches crescem, enquanto as matrículas na pré-escola, após três anos, sofrem uma relativa estagnação.

Gráfico 7: Tendência das matrículas públicas da Educação Infantil no estado de Alagoas (20052015)

No texto e no título, onde consta gráfico 7 ,

Leia-se gráfico 8, ficando como segue:

Considerando que a cooperação entre o estado de Alagoas e os municípios que o integram poderia correr pela destinação de recursos orçamentários na subfunção Educação Infantil, o gráfico 8 capta, para o período em que os dados estavam disponíveis, o "comportamento" desta opção pelas gestões governamentais. 
Gráfico 8: Gasto total em MDE na Educação Infantil no Estado de Alagoas (2005-2013)

No texto e no título, onde consta gráfico 8 ,

Leia-se gráfico 9, ficando como segue:

Por outro lado, o gráfico 9 apresenta dois picos, em que houve, de maneira proporcional ao total gasto com educação infantil pelo estado nos mesmos anos, maior gasto destinado esfera privada, nos anos de 2007 e 2010

Gráfico 9: Percentual de gasto registrado nas categorias econômicas selecionadas em relação ao gasto total com Educação Infantil no estado de Alagoas (2005-2013)

No texto e no título, onde consta gráfico 9 e gráfico 10 ,

Leia-se gráfico 10 e gráfico 11, ficando como segue:

O estado do Maranhão segue a mesma tendência de Alagoas na oferta pública, com aumento do atendimento de 0 a 3 anos e diminuição da pré-escola, a qual apresentou queda acentuada a partir de 2010, como demonstrado no gráfico 10. Contraditoriamente, nesse mesmo ano, ocorre um "pico" nos gastos totais em MDE com a educação infantil por parte do estado. (gráfico 11)

Gráfico 10: Tendência das matrículas públicas da Educação Infantil no estado do Maranhão (2005-2015)

Gráfico 11: Gasto total governo estadual em MDE na Educação Infantil - Maranhão (2005-2015)

No texto e no título, onde consta gráfico 11,

Leia-se gráfico 12, ficando como segue:

Conforme observado no gráfico 12, em 2012 e 2013, o Estado do Maranhão registrou 100\% dos recursos em MDE destinados para educação infantil, na categoria econômica 3.33.90.39 - Outros Serviços de Terceiros - Pessoa Jurídica, representando um valor de R $\$ 295.662,34$ no ano de 2012 e R $\$ 272.056,57$, em 2013.

Gráfico 12: Percentual de gasto na categoria econômica 3.33.90.39 - Outros Serviços de Terceiros - Pessoa Jurídica no estado do Maranhão (2005-2015) 